\title{
FRACTURE MECHANICS ANALYSES FOR INTERFACE CRACK PROBLEMS - A REVIEW
}

\author{
Ronald Krueger ${ }^{1}$ \\ National Institute of Aerospace \\ Hampton, VA, \\ Kunigal Shivakumar ${ }^{2}$, \\ North Carolina A\&T State University \\ Greensboro, NC \\ and \\ Ivatury S. Raju ${ }^{3}$ \\ NASA Langley Research Center, Hampton, VA
}

\begin{abstract}
Recent developments in fracture mechanics analyses of the interfacial crack problem are reviewed. The intent of the review is to renew the awareness of the oscillatory singularity at the crack tip of a bimaterial interface and the problems that occur when calculating mode mixity using numerical methods such as the finite element method in conjunction with the virtual crack closure technique. Established approaches to overcome the nonconvergence issue of the individual mode strain energy release rates are reviewed. In the recent literature many attempts to overcome the nonconvergence issue have been developed. Among the many approaches found only a few methods hold the promise of providing practical solutions. These are the resin interlayer method, the method that chooses the crack tip element size greater than the oscillation zone, the crack tip element method that is based on plate theory and the crack surface displacement extrapolation method. Each of the methods is validated on a very limited set of simple interface crack problems. However, their utility for a wide range of interfacial crack problems is yet to be established.
\end{abstract}

\section{Introduction}

Over the past two decades, the use of fracture mechanics has become common practice for characterizing the onset and growth of delaminations [1-3]. In order to predict delamination onset or growth, the calculated strain energy release rate components are

\footnotetext{
${ }^{1}$ Associate Research Fellow, Associate Fellow AIAA, Member ASC

2 Research Professor and Director, Center for Composite Materials Research, Department of Mechanical Engineering, Associate Fellow AIAA, Member ASME

${ }^{3}$ NASA Technical Fellow for Structures, NASA Engineering and Safety Center, Fellow AIAA, Member ASME, Member ASCE.
} 
compared to interlaminar fracture toughness properties which are measured over a range from pure mode I loading to pure mode II loading. Figure 1 shows such data (blue circles) for a typical carbon/epoxy material. Failure is expected when, for any given mixed mode ratio $G_{I I} / G_{T}$, the calculated total energy release rate, $G_{T}$, exceeds the interlaminar fracture toughness, $G_{c}$, shown as a curve fit through the experimental data [4].

Crack onset, propagation, and growth at bimaterial interfaces are of interest to a large community. In addition to increasing applications for the analysis composites [5-7], cracking has recently been investigated in conjunction with microelectronics [8-11], and piezoelectric bimaterials [12] as well as thin film interfaces [13]. Also, cracks that develop at the fiber-matrix interface in composites[14]. Cracks that propagate perpendicular to a bimaterial interface have also been of interest [15] [16]. In the current paper the attention, however, is limited to methods that are suitable to predict delamination onset, propagation and growth in composites, as well as face sheet/core disbonding in sandwich structures.

The objective of this paper is to renew the awareness of the oscillatory singularity at the crack tip at a bimaterial interface and the problems that occur when calculating mode mixity using numerical methods such as the finite element method in conjunction with the virtual crack closure technique (VCCT) [17-19]. The mathematical background of the oscillatory singularity at the crack tip at a bimaterial interface is discussed briefly. Established approaches to overcome the non-convergence issue of obtaining the individual mode strain energy release rates are reviewed and example cases are presented. New methods to provide straightforward practical solutions to easily obtain converged solutions for engineering applications are discussed and recommendations for future research are presented.

The paper is organized as follows: First, an overview of the bimaterial interface crack problem is given. Second, a brief overview of the virtual crack closure technique together with new developments in the methodology is presented. Third, recent developments in the analyses of interface crack problems are briefly discussed. Fourth, a more detailed description of several methods to obtain satisfactory mode separation is presented. A discussion follows and the paper ends with some concluding remarks.

\section{Bimaterial Interface Crack}

An interface crack of length $2 a$ between two materials $A$ and $B$ is shown in Figure 2, subjected to remote normal $S_{N}$ and tangential tractions $S_{T}$. For example, the two materials $A$ and $B$ in Figure 2 may be the neighboring plies in a composite laminate.

Williams [20] observed that the singularity at the tips of the crack along the interface between two dissimilar isotropic materials is of the form $\left(\frac{1}{2} \pm i \gamma\right)$ where

$$
\gamma=\frac{1}{2 \pi} \ln \left[\frac{\mu_{A}+\kappa_{A} \mu_{B}}{\mu_{B}+\kappa_{B} \mu_{A}}\right]=\frac{1}{2 \pi} \ln \left(\frac{1-\beta}{1+\beta}\right)
$$


with $\kappa_{j}=3-4 v_{j}$ is for plane strain conditions, $\mu_{j}$ is the shear modulus, $v_{j}$ is the Poisson's ratio for $j^{\text {th }}$ material and $j=A, B$. In equation (1), $\beta$ is known as the Dundurs parameter and is defined in terms of $\mu_{j}$ and $\kappa_{j}$ as

$$
\beta=\frac{\mu_{A}\left(\kappa_{B}-1\right)-\mu_{B}\left(\kappa_{A}-1\right)}{\mu_{A}\left(\kappa_{B}+1\right)+\mu_{B}\left(\kappa_{A}+1\right)}
$$

For orthotropic and anisotropic materials the singularity is of similar form and the $\gamma$ expression is much more complex than the isotropic case.

The stresses, $\boldsymbol{t}$, along the bondline (on the $\theta=0$ line) can be written in a form [21-23]

$$
\boldsymbol{t}=\left(\sigma_{y y}+i \sigma_{x y}\right)_{\theta=0}=\frac{\boldsymbol{K} \boldsymbol{r}^{i \gamma}}{\sqrt{2 \pi r}}
$$

and the relative displacements, $u_{R}$ behind the crack tip (at $x=a$ ) as

$$
\begin{aligned}
\boldsymbol{u}_{\boldsymbol{R}} & =(v+i u)_{\theta=\pi}-(v+i u)_{\theta=-\pi} \\
& =2\left(\frac{1-v_{A}}{\mu_{A}}+\frac{1-v_{B}}{\mu_{B}}\right) \frac{\boldsymbol{K} \boldsymbol{r}^{i \gamma}}{(1+2 i \gamma) \cosh (\pi \gamma)} \sqrt{\frac{\boldsymbol{r}}{2 \pi}}
\end{aligned}
$$

where $i=\sqrt{(-1)}$. In equations (3) and (4), $\boldsymbol{K}$ is the complex stress-intensity factor defined as [21]

$$
\boldsymbol{K}=\left(\boldsymbol{k}_{1}+\boldsymbol{i} \boldsymbol{k}_{2}\right) \sqrt{\pi} \cosh (\pi \gamma)
$$

The near-field solution in equations (3) and (4) suggests that the stresses very near the crack tip, $(r \rightarrow 0)$, oscillate (because of the $r^{i \gamma}$ term) and the crack faces interpenetrate each other in this region.

The mode-mixity phase angle, $\psi_{K}$, can be expressed as

$$
\psi_{K}=\arctan \left[\frac{\operatorname{Im}\left(K r^{i \gamma}\right)}{\operatorname{Re}\left(K r^{i \gamma}\right)}\right]
$$

where Im and Re are the imaginary and real parts, respectively, of the complex function in the brackets.

\section{Strain Energy Release Rates}

The strain energy release rate, $G_{T}$, can be calculated using Irwin's crack closure integral over a virtual crack closure length $\Delta a$, from equations (3) and (4), as 


$$
G_{T}=\lim _{\Delta a \rightarrow 0} \frac{1}{2 \Delta a} \int_{0}^{\Delta a} \boldsymbol{t}(\boldsymbol{r}) \cdot \boldsymbol{u}_{\boldsymbol{R}}(\Delta a-r) \cdot d r=4\left(\frac{1-v_{A}}{\mu_{A}}+\frac{1-v_{B}}{\mu_{B}}\right) \frac{\boldsymbol{K} \overline{\boldsymbol{K}}}{16 \cosh ^{2}(\pi \gamma)}
$$

where $\overline{\boldsymbol{K}}$ is the complex conjugate of $\boldsymbol{K}$. The strain energy release rate in equation (7) will be denoted as the total strain energy release rate, $G_{T}$. While the total strain energy release rate appears to control fracture of bimaterial plates, the mode I component of the strain energy release rate appears to correlate the experimental data better in fatigue type loading [24]. Also in composite materials a strong dependence of the experimentally determined fracture toughness $G_{c}$ on the individual mode strain energy release rates was observed as already shown in Figure 1. Therefore, in the literature considerable attention was devoted to the calculation of the individual mode strain energy release rates $[18,19$, 24-27]. Raju et al. [26] showed that for an interface crack between two dissimilar isotropic materials, the individual strain energy release rates take the form

$$
\begin{aligned}
G_{I} & =\lim _{\Delta a \rightarrow 0} \operatorname{Re}\left[\boldsymbol{C}+\boldsymbol{D} \cdot(\Delta a)^{i \gamma}\right] \\
G_{I I} & =\lim _{\Delta a \rightarrow 0} \operatorname{Re}\left[\boldsymbol{C}-\boldsymbol{D} \cdot(\Delta a)^{i \gamma}\right] \\
G_{T} & =G_{I}+G_{I I}=\lim _{\Delta a \rightarrow 0} \operatorname{Re}[2 \boldsymbol{C}]
\end{aligned}
$$

and

$$
\tan ^{2} \psi_{G}=\frac{G_{I I}}{G_{I}}
$$

where $\Delta a$ is the virtual crack closure length as shown in Figure 3. The parameters $C$ and $\boldsymbol{D}$ in equation (8) are complex constants. Equation (8) suggests that the individual strain energy release rates, $G_{I}$ and $G_{I I}$, depend on $\Delta a$ and have no well defined limits, while the total energy release rate, $G_{T}$, is independent of $\Delta a$ and has a very well defined limit. For homogeneous, isotropic materials, however, the results for mode mixity based on equations (6) and (9) are identical.

\section{The Virtual Crack Closure Technique : Overview and Recent Developments}

The virtual crack closure technique [17-19] is widely used for computing energy release rates based on results from continuum two-dimensional (2D) and solid threedimensional (3D) finite element (FE) analyses. The mode I and mode II components of the strain energy release rate, $G_{I}$ and $G_{I I}$ respectively are computed using VCCT as shown in Figure 4a for a 2D four-node element. For geometrically nonlinear analysis where large deformations may occur, both forces and displacements obtained in the global coordinate system need to be transformed into a local coordinate system $\left(x^{\prime}, y^{\prime}\right)$ which originates at the crack tip as shown in Figure 4a. The local crack tip system defines the tangential ( $x^{\prime}$ or mode II) and normal ( $y^{\prime}$ or mode I) coordinate directions at the crack tip in the deformed configuration. The terms $F_{x i}^{\prime}, F_{y i}^{\prime}$ are the forces at the crack tip at 
nodal point $i$ in the local $x$ and $y$ directions respectively. The terms $u_{\ell}^{\prime}, v_{\ell}^{\prime}$ and $u_{\ell^{*}}^{\prime}, v_{\ell^{*}}^{\prime}$ are the displacements at the corresponding nodal points $\ell$ and $\ell^{*}$ behind the crack tip. Note that $G_{I I I}$ is identical to zero in the $2 \mathrm{D}$ case. The extension to $3 \mathrm{D}$ is straightforward, as shown in Figure $4 \mathrm{~b}$ and the total energy release rate $G_{T}$ is calculated from the individual mode components as $G_{T}=G_{I}+G_{I I}+G_{I I I}$.

For many years the virtual crack closure technique was used mainly by scientists in universities, research institutions, and government laboratories, by implementing VCCT in their own specialized codes or in post-processing routines in conjunction with generalpurpose finite element codes. Recently, however, VCCT was implemented, as a standard analysis tool, into several commercial finite element codes such Abaqus/Standard ${ }^{\circledR 1}$, Nastran $^{\mathrm{TM} 2}$, Marc ${ }^{\mathrm{TM}}$ and ANSYS ${ }^{\circledR 3}$ [28-32] and, therefore, has become a more frequently used analysis tool.

With increasing three-dimensional simulations, the analysis along a curved or arbitrarily shaped front has been the focus of various new approaches. In reference [33], Li et al. developed a method to use VCCT in conjunction with a stepped mesh along a delamination front. A modified zigzag approach to approximate a crack front with an arbitrary shape was proposed by Liu et al. [34]. A simple and efficient algorithm to trace a moving delamination front with an arbitrary and changing shape was developed by Xie and Biggers [35]. Based on the applied algorithm, a delamination front can be defined by two vectors that pass through any point on the front. The normal and tangent vector for the local coordinate system can then be obtained based on the two delamination front vectors. This approach allows delamination growth to be analyzed by using stationary meshes and it does not require the use of meshes that are orthogonal to the delamination front.

A generalized method that allows arbitrary placement of the side nodes for quadratic elements was developed by Nairn [36]. This method included both standard elements, with mid-side nodes, and singularity elements, with quarter-point nodes, as special cases of one general equation [36]. The approach also accounted for traction-loaded cracks. The new derivation suggested that the proper nodal forces needed for crack closure calculations should be the so-called nodal edge forces, rather than the global or element forces from standard finite element analysis results.

Traditionally, VCCT has been used to study delamination propagation and growth where the delamination advance is constrained to the original interface plane. Recently, a new numerical method based on VCCT was proposed by Xie et al. [37, 38], which allows the calculation of strain energy release rates for cracks that kink. This method allows the evaluation of the mode I and mode II energy release rate at the tip of a kinking crack using only the nodal forces and displacements near the crack tip. This method may

\footnotetext{
${ }^{1}$ Abaqus/Standard ${ }^{\circledR}$ is a product of Dassault Systèmes Simulia Corp. (DSS), Providence, RI, USA

${ }^{2}$ Nastran $^{\mathrm{TM}}$ and Marc ${ }^{\mathrm{TM}}$ are manufactured by MSC.Software Corp., Santa Ana, CA, USA. NASTRAN ${ }^{\circledR}$ is a registered trademark of NASA

${ }^{3}$ ANSYS $^{\circledR}$ is a product of ANSYS, Inc., Canonsburg, PA, USA
} 
become of interest for analyzing the interaction of delamination propagation in one interface accompanied by matrix cracking, branching and subsequent delamination propagation at an adjacent interface.

An interface element that incorporates VCCT was developed by Qian and Xie [39] and used to study an example of dynamic crack propagation under mixed mode loading. Using the interface element approach, VCCT can be implemented into any open commercial finite element code that allows user-written subroutines. The interface element idea is similar to the interface element proposed earlier by Mabson et al. [40-42].

Under certain conditions, VCCT calculations yield small negative values of the mode components. This problem was investigated by Valvo [43], who found that the origins of these physically inconsistent predictions of the standard VCCT lie in the lack of energetic orthogonality between the crack-tip force components used to compute the mode components. A revised VCCT was presented which furnished a physically consistent partitioning of fracture modes that eliminate the calculations of negative energy release rate components. This was accomplished by associating the mode I and II contributions with the amounts of work done in a suitably defined two-step process of closure of the virtually extended crack.

\section{Recent developments for interface crack problems}

In this section, recent developments to evaluate mode mixity using VCCT and other approaches such as cohesive zone modeling, beam and plate modeling, and a method based on $M$-integral are presented.

\section{Calculating mode-mixity using the Virtual Crack Closure Technique (VCCT)}

Raju et al., in reference [26], implemented the virtual crack closure technique (VCCT) in a quasi three-dimensional finite element analysis. The individual mode components and the total energy release rate values for various bimaterial plates with isotropic, orthotropic, and anisotropic materials were evaluated. Reference [26] studied the problem of a laminated composite with an edge delamination. A typical FE model for an interface crack was presented in Figure 3. The total energy release rate and individual mode components of the strain energy release rates for a [0/35/-35/90]s laminate with symmetric delaminations at the 35/90 and -35/90 interfaces were calculated and analyzed. For all the bimaterial problems studied, the individual modes showed $\Delta a$ dependence while the total value of $G$ remained well defined and independent of $\Delta a$. Raju et al. [26] also showed that if the materials were chosen such that the Dundurs parameter $\beta \equiv 0$ then the individual as well as the total $G$ values are independent of $\Delta a$ and all have well defined limits.

The independence of the total value of $G$ was also reported by several investigators [22, 25, 27]. Specifically, Sun and Jih [27] and Dattaguru [25] observed the nonconvergence of the individual mode strain energy release rates and showed analytically that if the 
oscillatory terms are neglected, the mode I and mode II values tend to be equal to onehalf of the value of $G_{T}$ i.e. $G_{I}=G_{I I}=G_{T} / 2$ at the crack tip.

In a recent overview paper Agrawal and Karlsson [44] carefully reviewed and extended methods that characterize fracture at a bi-material interface, with a particular focus on evaluating the mode mixity using the virtual crack closure technique (VCCT). From their review, Agrawal and Karlsson concluded that:

- mode mixity based on the stress intensity factor can be calculated from the oscillating components of the strain energy release rate obtained by VCCT, using the derived expressions in reference [44],

- Sun and Jih [45], Chow and Atluri [46], and Toya [47] derived expressions for complex stress intensity factors using different methods. However, all these expressions are essentially identical and all the methods can be derived from one another,

- an approach developed by Bjerken and Persson [48] yields acceptable values of mode mixity with significantly less computational efforts when compared to the other methods presented in references [46, 47] and [45], and

- expressions suggested by Beuth [49] can also be related to the other approaches discussed.

Beuth presented a mode mixity based on strain energy release rate that is $\Delta a$ independent by introducing a normalizing length parameter. However, the $\Delta a$ independent mode mixity appears to be a mathematical quantity with no physical meaning. Nevertheless, it is suggested that it can be a useful parameter if care is taken in its interpretation [44]. Unfortunately, no possible interpretation of the quantity calculated by Beuth's expressions is suggested.

Although a comprehensive summary of the mathematical relationship between the methods is given, no relationship of the calculated values with the commonly used critical values and measured mixed-mode fracture toughnesses of a material or a bimaterial system is suggested or provided.

\section{Cohesive zone modeling}

The cohesive zone modeling approach has become a widely used tool for simulating delaminations due to the computational convenience and ease of implementation [50-57]. In this approach it is assumed that a narrow zone of vanishing thickness called the cohesive zone exists ahead of a crack tip or delamination front. The cohesive zone represents the fracture process zone. The upper and lower surfaces of the narrow zone are held together by forces called cohesive tractions. These tractions follow a cohesive constitutive law (traction-separation law) that relates the cohesive tractions to the separation displacements of the cohesive surfaces. Delamination onset or crack growth occurs when the separation at the end of the cohesive zone, which represents the physical crack tip, reaches a critical value at which the tractions vanish. The failure process is controlled by displacements and stresses, which are consistent with the usual strength of materials theory. Thus the problem of crack tip stress singularity found in the classical linear elastic fracture mechanics is avoided and the singularity is effectively buried in the element since the crack tip is not explicitly modeled. Special finite elements, called 
decohesion elements, with initially zero thickness, containing the traction-separation law can be formulated. These decohesion elements can be conveniently placed at any interface location in the intact model where delamination or cracking may occur. The modeling of an existing crack or flaw as required for VCCT to model the crack tip is not necessary in this approach. An extension to include modeling of fatigue crack growth under cyclic loading was recently presented by Naghipour et al. [58].

A new two-dimensional cohesive zone model, which is suitable to simulate the constitutive behavior of interface cracks in bimaterials, was developed by Freed and Banks-Sills [59]. Based upon experimental observations, a model was developed where the interface fracture toughness is not constant, but depends upon the mode mixity. For the presented approach the cohesive model may be described as an infinite set of cohesive laws, one for each discrete value of the phase angle $\psi$. For each cohesive model, the cohesive energy and cohesive strength are adjusted with respect to the phase angle $\psi$ to obtain a specific cohesive law for the current phase angle, so that only these two parameters are essential for this model. With this choice of parameters, the energy for separation $G_{I c}$ is consistent with the commonly used interface fracture toughness criterion.

Jin and Sun [60] reported issues, however, when cohesive zone modeling is used to simulate fracture at a bimaterial interface. It was found that for mixed-mode fracture in general, a selected single cohesive zone length may not meet the requirements that both the tensile and the shear stress singularities at the cohesive zone tip are cancelled simultaneously. The energy dissipation at the cohesive zone tip may therefore only be neglected when the initial stiffnesses of the cohesive model for both opening and shear modes are appropriately high. Also the length of the selected cohesive zone has to be set much greater than the characteristic length of the cohesive zone model in both cases of tension and shear.

\section{Methods based on beam and plate theory}

Recently, there appears to have been a renewed interest in analytical solutions for the calculation of mixed-mode energy release rates. The motivation arises from the desire to reduced modeling and analysis time of complicated three-dimensional finite element analysis. Analytical solutions based on beam and plate theory therefore become appealing. Bruno and Greco [61] proposed an analysis using an improved laminated plate model. The analysis was carried out by modeling the delaminated plate using either Kirchhoff or Mindlin plate assumptions for the individual layers. Comparisons with fracture mechanics results showed the validity of the proposed mechanical model to predict mode partition. In the approach suggested by Luo and Tong [62] the energy release rates in a cracked laminate are obtained analytically using a global - local method. Szekrényes [63] proposed another analytical plate theory approach and used a flexible joint model to determine the displacement and stress fields in symmetrically delaminated, layered composite plates subject to bending. The energy release rates were calculated using the 3D $J$-integral. 


\section{A methodology based on a conservative M-integral}

Banks-Sills, with several co-workers, focused on computational fracture mechanics using finite element analysis to study bimaterial interface fracture and compute complex stress intensity factors [64-70]. Over the past decade their research has also included the study of interlaminar fracture in composite laminates. An approach for calculating the energy release rate and the phase angles along the delamination front as well as measuring the interface fracture properties of a composite materials [68-70] was developed.

In their analysis approach, stress intensity factors along the delamination front are calculated first, using a conservative $M$-integral formulation. The $M$-integral formulation was first presented by Yau et al. [71]. Later this formulation was extended by Yau and Wang [72] for interface cracks between two homogeneous isotropic two-dimensional bodies. More recently, a three-dimensional $M$-integral using asymptotic stress was presented by Freed and Bank-Sills [73].

The first term of the asymptotic stress and displacement fields, which may be expressed by an oscillatory singularity and a square root singularity, were obtained by means of Stroh and Lekhnitskii formalisms for anisotropic material. The development of the approach was presented in great mathematical detail in reference [73]. The stress intensity factors obtained from the $M$-integral are then used to calculate the total energy release rate $G_{T}$ and the corresponding phase angles $\psi$ and $\phi$ along the front, where

$$
\begin{gathered}
G_{T}=\frac{1}{H_{1}}\left(K_{1}^{2}+K_{2}^{2}\right)+\frac{1}{H_{1}} K_{I I I}^{2} \\
\psi=\arctan \left[\frac{\operatorname{Im}\left(K L^{i \gamma}\right)}{\operatorname{Re}\left(K L^{i \gamma}\right)}\right]
\end{gathered}
$$

and

$$
\phi=\arctan \left[\sqrt{\frac{H_{1}}{H_{2}}} \frac{K_{I I I}}{\sqrt{K_{1}^{2}+K_{2}^{2}}}\right]
$$

specifically for a $0^{\circ} / 90^{\circ}$ interface [74]. The parameters $H_{1}$ and $H_{2}$ are functions of the material properties. The total energy release rate and the corresponding phase angles from equations (10-12) are compared to the mixed-mode fracture criterion to determine delamination propagation.

In general, a mixed-mode fracture criterion for a three-dimensional problem may be described as a relation between the three stress intensity factors or the critical energy release rate $G_{c}$ which depends on a function of the phase angles $\psi$ and $\phi$. It should be noted that the phase angle $\psi$ depends on an arbitrary length parameter $L$ while $\phi$ is length independent. The criterion used by Banks-Sills et al. [74] is based on the energy release rate given by 


$$
G_{c}=G_{1 c}\left(1+\tan ^{2} \psi\right)\left(1+\tan ^{2} \phi\right)
$$

where $G_{c}$ is the critical interface energy release rate and $G_{1 c}$ is the critical mode 1 energy release rate which is obtained as the average value from all tests as

$$
G_{1 c}=\frac{\left[\operatorname{Re}\left(K L^{i \gamma}\right)\right]^{2}}{H_{1}}
$$

Note that in equations (13) and (14) $G_{1 c}$ is not the traditional $G_{I c}$.

A Brazilian disk specimens, shown in Figure 5, is used to obtain the fracture parameters in equations (13) and (14). Note that the Brazilian disk specimens is different from the ASTM/ISO standard Double Cantilever Beam (DCB), End-Notched Flexure (ENF) and Mixed-Mode Bending (MMB) tests commonly used by the composites community. The fracture parameters are obtained using finite element analysis, which again is different from the current standards for which compliance calibration, the area method or simple equations based on beam theory are used to reduce the data. To date, validation of the method has only be established for $0^{\circ} / 90^{\circ}$ and $+45^{\circ} /-45^{\circ}$ interfaces. Details are given in reference [69]. Application examples for an embedded delamination in a cross-ply composite and through the width delaminations are presented in references [74, 75]. The validity of the method for general laminates is yet to be established.

\section{Additional methods to obtain satisfactory mode separation}

In this section, additional methods to obtain satisfactory individual modes are presented. These are the resin interlayer method, crack-tip element approach, and crack surface displacement extrapolation method are evaluated for their ability to obtain satisfactory mode separation. Each of these methods is presented along with application examples that demonstrate the effectiveness of the method.

\section{Resin interlayer method}

As an approach to eliminate the oscillatory crack-tip singularity at the bimaterial interface for a composite laminate, Raju et al. [26] performed analyses for a model where the delamination was located in a thin homogeneous isotropic layer similar to a resin layer that existed between the $-35 / 90$ plies of their edge-delaminated specimen. For this case the oscillatory component of the singularity vanished since the delamination was now located in a homogeneous isotropic material. The VCCT was used to calculate the total energy release rate $G_{T}$ as well as the mode I and mode II components. Results obtained from the model with resin layer showed that the individual mode components as well as the total strain energy release rates remained practically unchanged as the ratio, $\Delta a / h$, of crack tip element length, $\Delta a$, to ply thickness, $h$, decreased. However, in reference [76], no convergence for the individual mode components was observed when the interface crack configurations have extremely small resin layer thicknesses along with large stiffness differences between the layers on either side of the interface. 
Method based on choosing $\Delta$ a larger than oscillatory zone

Raju et al. [26] also reported that the individual mode components obtained from the interface model with the resin layer agreed well with those obtained from the models without resin layer when values of $\Delta a / h$ were either 0.25 or 0.5 . The maximum difference between the two approaches was reported to be less than $4 \%$ for the mode I and $2 \%$ for the mode II components. The results suggested that the size of the delamination tip elements, $\Delta a$, to be one-quarter to one-half of the ply thickness, $h$.

Sun and Jih [27] also found that the mode components depend on the choice of the crack tip element length $\Delta a$. However, in their analysis the mode mixity agreed well with the analytical solutions if the assumed crack extension was larger than the region of violent stress oscillation. For a calculated bimaterial constant $\gamma$ (also often referred to as $\varepsilon$ ) for a AS4 composite $(0.004,0.018$, and 0.038 for $0 / 15,0 / 45$, and $0 / 90$ interfaces respectively) it was found that the stress-oscillating zone is negligibly small. In particular for a 90/30 interface it was shown that the stress will not start oscillating until the distance is at the order of $10^{-12}$ of specimen thickness [77]. Based on these results it was suggested that for a range of $\Delta a / a$ ratios (where the mode I and mode II components were found to be almost constant) these constant values of $G_{I}$ and $G_{I I}$ may be used for practical purposes.

Krueger summarized these and similar results in a comprehensive review of the stateof-the-art of VCCT [18]. After a careful study of the published results Krueger concluded that for certain values of $\Delta a / h$ the variation in the individual-mode strain energy release rates is small as shown, in Figure 6a, and a recommended range of $\Delta a / h$ was proposed. A value of $\Delta a / h>1$ requires smearing ply properties for plies of different orientations as shown in Figure 6b, which is not acceptable if individual plies need to be modeled. At the other extreme, a value of $\Delta a / h<1 / 20$, violates the assumption of a homogeneous continuum since this value borders on the region where micromechanics should be used. As such, the recommended element size range is $1 / 20 \leq \Delta a / h \leq 1$. Variations in mode mixity between these bounds are typically very small and should prove acceptable for practical applications [18]. Furthermore, the literature shows that most analysts in tend to use element sizes in this range.

\section{Application Examples}

In this subsection, two examples that illustrate the effectiveness of the methods based on choice of $\Delta$ a larger than the oscillatory zone are presented.

Example of a stiffened shear panel with local three-dimensional modeling[78]. A square $(1016 \mathrm{~mm} \times 1016 \mathrm{~mm})$ panel made of IM7/8552 carbon/epoxy tape was reinforced with three stiffeners made of IM7/8552 carbon/epoxy plain weave fabric. During manufacturing, an artificial defect of about $82 \mathrm{~mm}$ in length was introduced at the termination of the center stiffener, thus creating a delamination at a bimaterial interface between a $-45^{\circ}$ unidirectional tape layer and a $0^{\circ}$ fabric layer. The stiffened panel was bolted to a steel picture frame (see Figure 7a) and subjected to shear loading. The shear loading caused the panel to buckle as shown 
in Figure 7a. The resulting out-of-plane deformation caused skin/stiffener separation to initiate at the location of the artificial defect. A typical finite element model of this panel is shown in Figure 7b. A small section of the stiffener foot and the panel skin in the vicinity of the embedded defect were modeled with a local 3D solid model as shown in the enlargement in Figure 7b. The mixed-mode strain energy release rates across the width of the stiffener foot were calculated using VCCT. A failure index $G_{T} / G_{c}$ was calculated by correlating the computed total energy release rate $G_{T}$ and mode mixity $G_{I I} / G_{T}$ with the mixed-mode failure criterion of the graphite/epoxy material similar to the one shown in Figure 1.

The objective of the research was to study the effect of the fidelity of the local 3D finite element model on the computed mixed-mode strain energy release rates and the failure index [78]. This study also included the introduction and modeling of a resin layer at the delaminated interface between the top skin ply $\left(-45^{\circ}\right.$ unidirectional tape) and the bottom of the flange $\left(0^{\circ}\right.$ fabric layer $)$. As the delamination exists in a homogeneous isotropic material (the resin interface layer) the oscillatory singularity at the crack tip of the bimaterial - as mentioned above does not exist. For convenience, the delamination was placed centrally within the resin layer. Therefore, the resin was modeled with two layers of elements with the delamination located between the two layers. Further details are discussed in reference [78]. The failure index $G_{T} / G_{c}$ distribution calculated along the delamination front, $s$, was compared to the distribution calculated from models without a resin layer as shown in Figure 8. For the models without a resin layer, a crack tip element length, $\Delta a$, had been chosen (approximately one ply thickness, $\Delta a / h \cong 1)$ in the range over which the mode mixity exhibits a reduced sensitivity to the value of $\Delta a$ as discussed above. The results from both approaches were in good agreement with each other and showed that the approaches yielded nearly equivalent results, confirming the results from Raju et al. [26] for the edge delamination problem. Based on the comparison, local models without the resin layer were used for all subsequent studies to reduce model complexity and analysis time [78].

Example of a multi-directional Single Leg Bending (SLB) specimen

To confirm the assumptions made about the range over which the mode mixity exhibits a reduced sensitivity to the value of $\Delta a$, as discussed above, a Single Leg Bending (SLB) specimen as shown in Figure 9a was studied in reference [18]. The SLB specimen was designed for mixed-mode fracture toughness testing and exhibits a nearly constant mode ratio of $G_{I I} / G_{T}=0.4$ (40\% mode II)[79]. A specimen with multidirectional layup was analyzed, where the delaminated interface was located between $\mathrm{a}+30^{\circ}$ and $-30^{\circ}$ ply $[80,81]$. The threedimensional model of the SLB specimen is shown in Figure 9b. Along the length of the model, a refined mesh of length $c$ was used in the vicinity of the delamination front. The influence of mesh size on computed mixed mode strain energy release rates was studied by keeping the length of the refined zone, $c$, constant and increasing the number of elements, $n$, in this zone, as shown in the detail of Figure $9 \mathrm{~b}$. The corresponding values of relative element size, $\Delta a / h$, and relative crack closure length, $\Delta a / a$, are shown in the insert. 
The influence of mesh refinement on the total strain energy release rate distribution $G_{T}$ across the normalized width, $y / B$, is shown in Figure 10. Only very long elements $(\Delta a=c / n=1 \mathrm{~mm} ; \Delta a / h=8)$ need to be avoided since the model is too coarse to yield any sensible results. The results for the other models basically agree very well with one another. The distribution of the mixed mode ratio $G_{I I} / G_{T}$ is fairly constant at about $35 \%$ mode II across almost the entire width of the specimen as shown in Figure 11. For the range studied, only a small dependence of computed mixed mode ratio on element size $\Delta a / h$ was observed.

Similar results were also obtained in a related investigation, in which mixed-mode energy release rates were computed for an ENF specimen with the same layup and interface location as the SLB specimen [80, 82]. This study indicated that the computed energy release rates, $G_{I I}$ and $G_{I I I}$, did not exhibit a significant variation when $\Delta a / h$ was kept within the suggested range. The results confirm the suggestion made above that element lengths be chosen within lower and upper bounds.

These methods based on choice of $\Delta a$ larger than the oscillatory zone are a convenient practical engineering approach based on experience. However, this simple approach may be limited to cases where the material mismatch is insignificant and the bimaterial constant, $\gamma$, is small. For general interface cracks along a bimaterial interface, where there is a significant mismatch in material properties and stiffnesses, this issue is much more difficult to resolve. These significant mismatches are observed for coatings on substrates in the electrical chip industry [8] or for sandwich structures with stiff face sheets and compliant cores [76].

\section{Crack tip element (CTE) approach}

The most comprehensive of all methodologies based on plate theory is the so-called crack tip element (CTE) approach developed by Davidson with several co-workers [8387] over the past 20 years. His overall prediction methodology includes the analysis of the energy release rate and the mode mixity along the delamination front in a structure as well as the development of a suitable mixed-mode fracture criterion [88-90]. The proposed mixed-mode fracture criterion is based on fracture toughness testing using simple standard type specimens such as the DCB, ENF and MBB specimen. The proposed mixed-mode fracture criterion is similar to the criterion shown in Figure 1. The Single Leg Bending (SLB) specimen, for mixed-mode testing at approximately constant $40 \%$ mode II was also introduced [79]. The methodology provides a straightforward practical solution for engineering applications.

A linear elastic crack-tip element for two-dimensional analysis was developed first and then extended and refined for practical applications [83] [84]. Analytical expressions were derived for the total energy release rate and mode mixity based on plate theory force and moment resultants near the crack tip as shown in Figure 12a. The element may be used for cracks within or between homogeneous, isotropic, or orthotropic layers, or for 
delaminations in laminated composites. After successful application to two-dimensional problems, the method was extended and a 3D crack tip element was developed as shown in Figure $12 \mathrm{~b}[85,86]$. Classical plate theory was used to derive the equations for the total energy release rate and mode mix. An additional mode mixity parameter, $\Omega$, is required to complete the mode mixity decomposition. This parameter depends upon the elastic and geometrical properties of the materials above and below the crack plane, but not on the loading. A relatively simple finite element model may be used to determine the mode mixity parameter. Pre-calculated values of $\Omega$ were also presented for a large number of cases [83]. For bimaterial interfaces where an oscillatory singularity occurs at the crack tip, an approach was also described which allows a unique, physically meaningful value of mixed mode ratio to be defined [83]. Davidson refers to this approach as the $\beta=0$ approach, where the generalized Dundurs parameter $\beta$ is taken equal to zero only in the finite element model that is used to to calculate $\Omega$. Setting $\beta=0$ causes the bimaterial constant $\gamma$ in equation (1) (also often referred to as $\varepsilon$ ) to be zero and eliminates the oscillating singularity at the crack tip [91, 92]. Setting $\beta=0$ is accomplished by altering the Poission's ratios $v_{13}$ or $v_{23}$ of one of the layers at the interface. The elastic moduli, however, need to be altered in a manner such that $\beta=0$ while the total energy release and other significant parameters remain unaffected. With $\beta=0$ and $\gamma=0$ the mode mixity parameter $\Omega$ can be calculated as

$$
\sin \Omega=\frac{-\sqrt{G_{I}}}{N_{c} \sqrt{c_{11}}}
$$

Here, $N_{\mathrm{c}}$ is the concentrated crack tip force and $c_{11}$, is a function of the material properties and layup of the plate. The procedure is described in full detail in reference [83].

For practical purposes, the energy release rate distribution along the delamination front is obtained from each crack tip element along the delamination front. Each crack tip element is made of a generic set of four elements as shown in Figure 12c. The total energy release rate $G_{T}$ is obtained by a plate-theory-based crack closure procedure as

$$
G_{T}=\frac{1}{2} \sum_{j=1}^{2}\left(\Delta N_{i} \Delta \varepsilon_{i}^{0}+\Delta M_{i} \Delta \kappa_{i}^{0}\right)_{j}, \quad i=1,2,6
$$

In order to obtain the quantities $\Delta N_{i}, \Delta M_{i}, \Delta \varepsilon_{i}^{o}$ and $\Delta \kappa_{i}$ for each crack tip element along the front, the plate theory forces, $\left\{N_{1}, N_{2}, N_{6}\right\}$ and moments $\left\{M_{1}, M_{2}, M_{6}\right\}$, obtained at the centroids of the four elements are first used with laminated plate theory to obtain the strains, $\varepsilon$, and curvatures, $\kappa$, in each of the cracked regions. The mode I and mode II components can be calculated as

$$
G_{I}=\frac{1}{2} \quad\left[-\sqrt{c_{11}} N_{c} \sin \Omega+\sqrt{c_{22}} M_{c} \cos (\Omega+\Gamma)\right]^{2}
$$


where

$$
G_{I I}=\frac{1}{2} \quad\left[\sqrt{c_{11}} N_{c} \cos \Omega+\sqrt{c_{22}} M_{c} \sin (\Omega+\Gamma)\right]^{2}
$$

$$
\sin \Gamma=\frac{c_{12}}{\sqrt{c_{11} C_{22}}}
$$

Here, $N_{\mathrm{c}}$ and $M_{\mathrm{c}}$ are the concentrated crack tip force and moment, respectively. The $c_{11}$, $c_{22}$ and $c_{12}$ terms are functions of the material properties and layup of the plate which are obtained from the inverse of the reduced stiffness matrix used in classical laminated plate theory $[85,86,88,93]$. The mode III component is calculated from these results as

$$
G_{I I I}=G-G_{I}-G_{I I}
$$

Additional details on the 3D CTE analyses are presented in reference [85]. In a detailed application example, delamination onset from an embedded defect is predicted using the 3D CTE analysis [86]. The defect is located between the stiffener foot and the skin of a hat stiffened specimen subjected to tension and bending. Good correlation with delamination growth measured in related experiments was observed.

Recently, Mikulik et al. [94] investigated the accuracy of VCCT and CTE to predict the initiation and growth of delaminations for the development of a specimen with multiple delaminations at several interfaces. Their investigation may be regarded as an independent verification of the CTE approach. The predictions correlated very well with the test data and both numerical approaches demonstrated the capability to identify the critical delamination interface and accurately capture the initiation load levels. Mikulik et al. concluded that fracture mechanics based approaches can be used for the prediction of multi-level delamination propagation.

\section{Crack Surface Displacement Extrapolation (CSDE) method}

Sandwich constructions used in aerospace vehicle structures generally consist of a low density core between two stiff surface layers (face sheets) to achieve lightweight structures with high stiffness and strengths. Flaws in the form of disbonds between the face sheet and the core may reduce the load-bearing capacity of the structure because of the loss of load transfer between the face sheet and the core. Such a disbond generally constitutes an interfacial crack between two widely dissimilar materials [95]. Smith and Shivakumar [96] used the total energy release rate $G_{T}$ to analyze their Cracked Sandwich Beam specimen to avoid issues with respect to mode separation that could occur when using VCCT. Wang and Zhang [97] presented a new analytical solution for the energy release rate and the phase angle at an interface crack in a sandwich based on interface fracture mechanics solutions and composite beam theory.

A promising method for the prediction of disbond propagation at the sandwich face sheet/core interface was suggested by Berggreen et al. [98, 99]. The CSDE method is based on the complex stress intensity factor $K$ defined in equation (5) and the so-called Crack Surface Displacement technique proposed by Matos et al. [100].

The total energy release rate $G_{T}$ and the mode mixity phase angle $\psi_{K}$ proposed in [92] 


$$
\psi_{K}=\arctan \left[\frac{\operatorname{Im}\left(K h^{i \gamma}\right)}{\operatorname{Re}\left(K h^{i \gamma}\right)}\right]
$$

can be expressed in terms of the relative crack flank displacements $\delta_{x}$ and $\delta_{y}$ shown in Figure 13a as

$$
\psi_{K}=\arctan \left(\sqrt{\frac{H_{22}}{H_{11}}} \frac{\delta_{x}}{\delta_{y}}\right)-\varepsilon \ln \left(\frac{|x|}{h}\right)+\arctan (2 \gamma)
$$

and

$$
G_{T}=\frac{\pi\left(1+4 \gamma^{2}\right)}{8 H_{11}|x|}\left(\frac{H_{11}}{H_{22}} \delta_{y}^{2}+\delta_{x}^{2}\right)
$$

where $h$ is the characteristic length of the problem and is chosen here as the face thickness. The constants $H_{11}, H_{22}$, and the oscillatory index $\gamma$ are dependent on the materials at the interface.

The mode-mixity and energy release rate can be calculated using equations $(22,23)$. The relative nodal displacements of the crack flanks are obtained from a finite element analysis. Therefore, both the mode-mixity, $\psi_{K}$, and $G_{T}$ will be affected by the oscillations near the crack tip. However, these effects are believed to be small away from crack tip zone and therefore have no practical importance. This argument is similar to the assumption made earlier for a practical solution of the mode mixity which can be obtained if the crack tip element length $\Delta a$ was larger than the region of violent stress oscillation [27]. As shown in Figure 13b, where the total energy release rate $G_{T}$ (solid blue line) was plotted for crack flank node pairs (solid blue circles), the oscillations vanish with increasing distance from the crack tip. A similar graph can be plotted for the mode-mixity. To avoid the oscillations in the numerical error zone, only the relative crack flank displacements obtained in the evaluation zone are used in the Crack Surface Displacement Extrapolation method. The results obtained are simply linearly extrapolated into the crack tip (red star in Figure 13b). The extrapolation can be performed separately for the total energy release rate, $G_{T}$, and the mode-mix, $\psi_{K}$, but normally it is sufficient to do this numerical extrapolation once for $G_{T}$ and then reuse the linear extrapolation parameters to obtain the mode mixity curve. Results for a rectangular sandwich plate with a circular disbond were presented where the computed energy release rate and mode mixity for the structure were compared to measured fracture toughness values [98, 99].

In another example where the fracture of a sandwich specimen loaded with axial forces and bending moments was analyzed, the CSDE method was used to calculate the phase angle [101, 102]. Face sheet/core fatigue crack growth in foam-cored sandwich composites was examined by Manca et al.al [103] using the mixed mode bending (MMB) test method. The phase angle, $\psi$, and energy release rate, $G$, were both determined from 
two-dimensional plane strain finite element results using the CSDE method. The method was also applied in a recently proposed accelerated simulation scheme for fatigue crack growth in a bimaterial interface, which was demonstrated to simulate fatigue crack growth in the face sheet/core interface of a sandwich beam [104].

\section{Discussion}

Although many new methods and approaches are presented in the literature for the interface crack problem, only a few approaches appear to be of practical use and capable of application to general cases and real world structural problems. Until now, the community at large has not yet found a consensus on an approach or a set of approaches. New methodologies need to provide analysis tools to determine the mixed-mode fracture parameters along an arbitrarily shaped crack or delamination front located at a bimaterial interface in a three-dimensional solid. In order to be successful, these new methodologies simultaneously need to recommend methods that are suitable for fracture toughness testing. Relatively simple specimens and uncomplicated test procedures should be developed to generate the data required for use in a mixed-mode fracture criterion. Any mixed-mode fracture criterion developed can then be used in conjunction with the analysis results to determine crack onset and growth.

\section{Concluding Remarks}

Cracks at bimaterial interfaces are common in composites, microelectronic materials, film interfaces, etc. To be able to predict the fracture behavior and perform damage tolerance evaluations of these materials and structural components, a thorough understanding of behavior of cracks located at bimaterial interfaces is needed. Williams showed more than a half a century ago, that in addition to the classical square root singularity at the crack tip, there exists an oscillatory singularity for cracks located at a bimaterial interface. The oscillatory singularity leads to some unsatisfactory consequences. Several investigators over the past three decades showed that when numerical methods, such as the finite element method, are used to evaluate the total and individual mode strain energy release rates, the individual modes do not show convergence as the mesh size is refined near the crack tip. The intent of the review was to renew the awareness of the oscillatory singularity at the crack tip of a bimaterial interface and the problems that occur when calculating mode mixity using numerical methods such as the finite element method in conjunction with the virtual crack closure technique.

Established approaches to overcome the non-convergence issue of the individual mode strain energy release rates were reviewed. In the recent literature many attempts to overcome the nonconvergence issue have been developed. Among the many approaches found only a few methods hold the promise of providing practical solutions. These are the resin interlayer method, the method that chooses the crack tip element size greater than the oscillation zone, the crack tip element method that is based on plate theory and 
the crack surface displacement extrapolation method. Each of the methods was validated on a very limited set of simple interface crack problems. However, their utility for a wide range of interfacial crack problems is yet to be established.

\section{References}

1. O'Brien, T. K. "Fracture Mechanics of Composite Delamination," Asm Handbook, Volume 21, Composites. ASM International, 2001, pp. 241-245.

2. "Delamination Onset Analysis," Polymer Matrix Composites: Materials Usage, Design, and Analysis, Composite Materials Handbook (Cmh-17). Vol. 3, SAE International, 2012.

3. Raju, I. S., and O'Brien, T. K. "Fracture Mechanics Concepts, Stress Fields, Strain Energy Release Rates, Delamination and Growth Criteria," Delamination Behaviour of Composites. Woodhead Publishing in Materials, 2008, pp. 3-27.

4. Benzeggagh, M. L., and Kenane, M. "Measurement of Mixed-Mode Delamination Fracture Toughness of Unidirectional Glass/Epoxy Composites with Mixed-Mode Bending Apparatus," Composites Science and Technology, Vol. 56, No. 4, 1996, pp. 439-449.

5. Liu, P. F., Hou, S. J., Chu, J. K., Hu, X. Y., Zhou, C. L., Liu, Y. L., Zheng, J. Y., Zhao, A., and Yan, L. "Finite Element Analysis of Postbuckling and Delamination of Composite Laminates Using Virtual Crack Closure Technique," Composite Structures, Vol. 93, No. 6, 2011, pp. 15491560.

6. Pietropaoli, E., and Riccio, A. "A Global/Local Finite Element Approach for Predicting Interlaminar and Intralaminar Damage Evolution in Composite Stiffened Panels under Compressive Load," Applied Composite Materials, Vol. 18, No. 2, 2011, pp. 113-125.

7. Pietropaoli, E., and Riccio, A. "Formulation and Assessment of an Enhanced Finite Element Procedure for the Analysis of Delamination Growth Phenomena in Composite Structures," Composites Science and Technology, Vol. 71, No. 6, 2011, pp. 836-846.

8. Auersperg, J., Dudek, R., Oswald, J., and Michel, B. "Interaction Integral and Mode Separation for BEOL-Cracking and -Delamination Investigations under 3d-Ic Integration Aspects," 12th International Conference on Thermal, Mechanical and Multiphysics Simulation and Experiments in Microelectronics and Microsystems, EuroSimE. 2011.

9. Ikeda, T., Nagai, M., Yamanaga, K., and Miyazaki, N. "Stress Intensity Factor Analyses of Interface Cracks between Dissimilar Anisotropic Materials Using the Finite Element Method," Engineering Fracture Mechanics, Vol. 73, No. 14, 2006, pp. 2067-2079.

10. Nomura, Y., Ikeda, T., and Miyazaki, N. "Stress Intensity Factor Analysis at an Interfacial Corner between Anisotropic Bimaterials under Thermal Stress," Engineering Fracture Mechanics, Vol. 76, No. 2, 2009, pp. 221-235.

11. Nomura, Y., Ikeda, T., and Miyazaki, N. "Stress Intensity Factor Analysis of a Three-Dimensional Interfacial Corner between Anisotropic Bimaterials under Thermal Stress," International Journal of Solids and Structures, Vol. 47, No. 14-15, 2010, pp. 1775-1784.

12. Ou, Z. C., and Wu, X. "On the Crack-Tip Stress Singularity of Interfacial Cracks in Transversely Isotropic Piezoelectric Bimaterials," International Journal of Solids and Structures, Vol. 40, 2003, pp. 7499-7511.

13. Beom, H. G., Cui, C. B., and Jang, H. S. "Dependence of Stress Intensity Factors on Elastic Constants for Cracks in an Orthotropic Bimaterial with a Thin Film," International Journal of Solids and Structures, Vol. 49, No. 23-24, 2012, pp. 3461-3471.

14. Mantič, V., and García, I. G. "Crack Onset and Growth at the Fibre-Matrix Interface under a Remote Biaxial Transverse Load. Application of a Coupled Stress and Energy Criterion," International Journal of Solids and Structures, Vol. 49, No. 17, 2012, pp. 2273-2290.

15. Jha, M., Charalambides, P. G., and Ballarini, R. "Near-Tip Mode-I Elastic Fields in Bimaterial Layered Systems," International Journal of Solids and Structures, Vol. 34, No. 15, 1997, pp. 1849-1871.

16. Yilan, K., and Hua, L. "Investigation of near-Tip Displacement Fields of a Crack Normal to and 
Terminating at a Bimaterial Interface under Mixed-Mode Loading," Engineering Fracture Mechanics, Vol. 69, No. 18, 2002, pp. 2199-2208.

17. Rybicki, E. F., and Kanninen, M. F. "A Finite Element Calculation of Stress Intensity Factors by a Modified Crack Closure Integral," Eng. Fracture Mech., Vol. 9, 1977, pp. 931-938.

18. Krueger, R. "Virtual Crack Closure Technique: History, Approach and Applications," Applied Mechanics Reviews, Vol. 57, No. 2, 2004, pp. 109-143.

19. "Calculation of Strain Energy Release Rate Interlaminar Fracture Mechanics," Polymer Matrix Composites: Materials Usage, Design, and Analysis, Composite Materials Handbook (CMH-17). Vol. 3, SAE International, 2012.

20. Williams, M. L. "The Stresses around a Fault or Crack in Dissimilar Media," Bulletin of the Seismological Society of America, Vol. 49, 1959, pp. 199-204.

21. Erdogan, F. "Stress Distribution in Bonded Dissimilar Materials with Cracks," J. Appl. Mech., Trans. ASME, Vol. 32, 1965, pp. 403-410.

22. Rice, J. R. "Elastic Fracture Mechanics Concepts for Interface Cracks," J. Appl. Mech., Trans ASME, Vol. 55, 1988, pp. 98-103.

23. Rice, J. R., and Sih, G. C. "Plane Problems of Cracks in Dissimilar Media," J. Appl. Mech., Trans. ASME, Vol. 32, 1965, pp. 418-423.

24. O'Brien, T. K. "Mixed-Mode Strain Energy Release Rate Effect on Edge Delamination," ASTM STP 836, 1984, pp. 125-142.

25. Dattaguru, B., Venkatesha, K. S., Ramamurthy, T. S., and Buchholz, F. G. "Finite Element Estimates of Strain Energy Release Rate Components at the Tip of an Interface Crack under Mode I Loading," Enineering Fracture Mechanics, Vol. 49, No. 3, 1994, pp. 451-463.

26. Raju, I. S., Crews, J. H., and Aminpour, M. A. "Convergence of Strain Energy Release Rate Components for Edge-Delaminated Composite Laminates," Eng. Fracture Mech., Vol. 30, No. 3, 1988, pp. 383-396.

27. Sun, C. T., and Jih, C. J. "On Strain Energy Release Rates for Interfacial Cracks in Bi-Material Media," Eng. Fracture Mech., Vol. 28, No. 1, 1987, pp. 13-20.

28. "Vcct for Abaqus - User's Manual." ABAQUS, 2005.

29. "Abaqus/Standard 6.12 User's Manual," Dassault Systèmes Simulia Corporation, Providence, RI, USA, 2012.

30. "Marc ${ }^{\mathrm{TM}}$ and Mentat ${ }^{\mathrm{TM}} 2008$ R1 User Manuals," MSC.Software Corporation, Santa Ana, CA, USA., 2008.

31. "MD Nastran ${ }^{\mathrm{TM}} 2008$ R1 Documentation," MSC.Software Corporation, Santa Ana, CA, USA, 2008.

32. Lin, G. "Crack Growth Simulation with VCCT Techniques in Ansys," draft ANSYS, Inc., 2011.

33. Li, X., Ferrie, C., Nottorf, E., and Portanova, M. "Virtual Crack Closure Technique on Stepped Crack Fronts (Vect-S)," AHS Forum. 2008.

34. Liu, Y.-P., Chen, C.-Y., and Li, G.-Q. "A Modified Zigzag Approach to Approximate Moving Crack Front with Arbitrary Shape," Engineering Fracture Mechanics, Vol. 78, No. 2, 2011, pp. 234-251.

35. Xie, D., and Biggers, S. B. "Strain Energy Release Rate Calculation for a Moving Delamination Front of Arbitrary Shape Based on the Virtual Crack Closure Technique. Part I: Formulation and Validation," Engineering Fracture Mechanics, Vol. 73, No. 6, 2006, pp. 771-785.

36. Nairn, J. A. "Generalized Crack Closure Analysis for Elements with Arbitrarily-Placed Side Nodes and Consistent Nodal Forces," International Journal of Fracture, Vol. 171, 2011, pp. 1122.

37. Xie, D., Waas, A. M., Shahwan, K. W., Schroeder, J. A., and Boeman, R. G. "Computation of Energy Release Rates for Kinking Cracks Based on Virtual Crack Closure Technique," CmesComputer Modeling in Engineering \& Sciences, Vol. 6, No. 6, 2004, pp. 515-524.

38. Xie, D., Waas, A. M., Shahwan, K. W., Schroeder, J. A., and Boeman, R. G. "Fracture Criterion for Kinking Cracks in a Tri-Material Adhesively Bonded Joint under Mixed Mode Loading," Engineering Fracture Mechanics, Vol. 72, No. 16, 2005, pp. 2487-2504.

39. Qian, Q., and Xie, D. "Analysis of Mixed-Mode Dynamic Crack Propagation by Interface Element Based on Virtual Crack Closure Technique " Engineering Fracture Mechanics, Vol. 74, No. 5, 2007, pp. 807-814.

40. Mabson, G., Deobald, L., and Dopker, B. "Fracture Interface Elements," FAA-ASTM D30 
Workshop on Computational Fracture Mechanics for Composites, Salt Lake City, Utah. U.S. Department of Transportation, Federal Aviation Administration, 2004.

41. Deobald, L., Mabson, G., Dopker, B., Hoyt, D., Baylor, J., and Graesser, D. "Interlaminar Fatigue Elements for Crack Growth Based on Virtual Crack Closure Technique," 48th AIAA/ASME/ASCE/AHS/ASC Structures, Structural Dynamics, and Materials Conference, Honolulu, Hawaii. AIAA-2007-2091, American Institute of Aeronautics and Astronautics, 2007.

42. Mabson, G. E., Deobald, L. R., Dopker, B., Hoyt, D. M., Baylor, J. S., and Graesser, D. L. "Fracture Interface Elements for Static and Fatigue Analysis," 16th International Conference on Composite Materials (ICCM-16). Kyoto, Japan, 2007.

43. Valvo, P. S. "A Revised Virtual Crack Closure Technique for Physically Consistent Fracture Mode Partitioning," International Journal of Fracture, Vol. 173, No. 1, 2012, pp. 101-114.

44. Agrawal, A., and Karlsson, A. M. "Obtaining Mode Mixity for a Bimaterial Interface Crack Using the Virtual Crack Closure Technique," Internationl Journal of Fracture, Vol. 141, No. 1-2, 2006, pp. 75-98.

45. Sun, C. T., and Qian, W. "The Use of Finite Extension Strain Energy Release Rates in Fracture of Interfacial Cracks," Int. J. of Solids and Structures, Vol. 34, No. 20, 1997, pp. 2595-2609.

46. Chow, W. T., and Atluri, S. N. "Finite Element Calculation of Stress Intensity Factors for Interfacial Crack Using Virtual Crack Closure Integral," Computational Mechanics, Vol. 16, 1995, pp. 417-425.

47. Toya, M. "On Mode I and Mode Ii Energy Release Rates of an Interface Crack," International Journal of Fracture, Vol. 56, 1992, pp. 345-352.

48. en, C. B., and Persson, C. "A Numerical Method for Calculating Stress Intensity Factors for Interface Cracks in Bimaterials," Engineering Fracture Mechanics, Vol. 68, 2001, pp. 235-246.

49. Beuth, J. L. "Separation of Crack Extension Modes in Orthotropic Delamination Models," International Journal of Fracture, Vol. 77, 1996, pp. 305-321.

50. Tvergaard, V. "Predictions of Mixed Mode Interface Crack Growth Using a Cohesive Zone Model for Ductile Fracture," Journal of the Mechanics and Physics of Solids, Vol. 52, No. 4, 2004, pp. 925-940.

51. Camanho, P. P., Davila, C. G., and Pinho, S. T. "Fracture Analysis of Composite Co-Cured Structural Joints Using Decohesion Elements," Fatigue \& Fracture of Engineering Materials \& Structures, Vol. 27, No. 9, 2004, pp. 745-757.

52. Turon, A., Dávila, C. G., Camanho, P. P., and Costa, J. "An Engineering Solution for Mesh Size Effects in the Simulation of Delamination Using Cohesive Zone Models," Engineering Fracture Mechanics, Vol. 74, No. 10, 2007, pp. 1665-1682.

53. Wang, W., and Davalos, J. F. "Evaluation of Facesheet-Core Delamination by Cohesive Zone Model," American Society for Composites - 20th Technical Conference, Drexel University, Philadelphia, PA. DEStech Publications, Inc., 2005.

54. Camanho, P. P., and Dávila, C. G. "Mixed-Mode Decohesion Finite Elements for the Simulation of Delamination in Composite Materials." NASA-TM-2002-211737, NASA Langley Research Center, Hampton, VA, 2002.

55. Bui, V. Q., Iannucci, L., Robinson, P., and Pinho, S. T. "A Coupled Mixed-Mode Delamination Model for Laminated Composites," Journal of Composite Materials, Vol. 45, No. 16, 2011, pp. 1717-1729.

56. Davidson, P., Waas, A. M., and Yerramalli, C. S. "Experimental Determination of Validated, Critical Interfacial Modes I and Ii Energy Release Rates in a Composite Sandwich Panel," Composite Structures, Vol. 94, No. 2, 2012, pp. 477-483.

57. Goutianos, S., and Sørensen, B. F. "Path Dependence of Truss-Like Mixed Mode Cohesive Laws," Engineering Fracture Mechanics, Vol. 91, 2012, pp. 117-132.

58. Naghipour, P., Bartsch, M., and Voggenreiter, H. "Simulation and Experimental Validation of Mixed Mode Delamination in Multidirectional Cf/Peek Laminates under Fatigue Loading," International Journal of Solids and Structures, Vol. 48, No. 6, 2011, pp. 1070-1081

59. Freed, Y., and Banks-Sills, L. "A New Cohesive Zone Model for Mixed Mode Interface Fracture in Bimaterials," Engineering Fracture Mechanics, Vol. 75, No. 15, 2008, pp. 4583-4593.

60. Jin, Z. H., and Sun, C. T. "Cohesive Zone Modeling of Interface Fracture in Elastic Bi-Materials," Engineering Fracture Mechanics, Vol. 72, No. 12, 2005, pp. 1805-1817.

61. Bruno, D., and Greco, F. "Mixed Mode Delamination in Plates: A Refined Approach," 
International Journal of Solids and Structures, Vol. 38, No. 50-51, 2001, pp. 9149-9177.

62. Luo, Q., and Tong, L. "Analytic Formulas of Energy Release Rates for Delamination Using a Global-Local Method," International Journal of Solids and Structures, Vol. 49, 2012, pp. 33353344.

63. Szekrényes, A. "Interlaminar Stresses and Energy Release Rates in Delaminated Orthotropic Composite Plates," International Journal of Solids and Structures, Vol. 49, No. 18, 2012, pp. 2460-2470.

64. Banks-Sills, L., and Sherman, D. "Comparison of Methods for Calculating Stress Intensity Factors with Quarter-Point Elements," International Journal of Fracture, Vol. 32, No. 2, 1986, pp. 127140.

65. Banks-Sills, L. "Application of the Finite Element Method to Linear Elastic Fracture Mechanics," Applied Mechanics Reviews, Vol. 44, No. 10, 1991, pp. 447-461.

66. Banks-Sills, L., and Ashkenazi, D. "A Note on Fracture Criteria for Interface Fracture," International Journal of Fracture, Vol. 103, 2000, pp. 177-188.

67. Banks-Sills, L., Travitzky, N., and Ashkenazi, D. "Interface Fracture Properties of a Bimaterial Ceramic Composite," Mechanics of Materials, Vol. 32, 2000, pp. 711-722.

68. Banks-Sills, L., Travitzky, N., Ashkenazi, D., and Eliasi, R. "A Methodology for Measuring Interface Fracture Properties of Composite Materials," International Journal of Fracture, Vol. 99, No. 2, 1999, pp. 143-160.

69. Banks-Sills, L., Boniface, V., and Eliasi, R. "Development of a Methodology for Determination of Interface Fracture Toughness of Laminate Composites-the $0^{\circ} / 90^{\circ}$ Pair," International Journal of Solids and Structures, Vol. 42, No. 2, 2005, pp. 663-680.

70. Banks-Sills, L. e., Freed, Y., Eliasi, R., and Fourman, V. "Fracture Toughness of the $+45^{\circ} /-45^{\circ}$ Interface of a Laminate Composite," International Journal of Fracture, Vol. 141, 2006, pp. 195210.

71. Yau, J. F., Wang, S. S., and Corten, H. T. "A Mixed-Mode Crack Analysis of Isotropic Solids Using Conservation Laws of Elasticity," Journal of Applied Mechanics, Vol. 47, No. 2, 1980, pp. 335-341.

72. Yau, J. F., and Wang, S. S. "An Analysis of Interface Cracks between Dissimilar Isotropic Materials Using Conservation Integrals in Elasticity," Engineering Fracture Mechanics, Vol. 20, 1984, pp. 423-432.

73. Freed, Y., and Banks-Sills, L. "A through Interface Crack between a $\pm 45 \circ$ Transversely Isotropic Pair of Materials," International Journal of Fracture, Vol. 133, No. 15, 2005, pp. 1-41.

74. Banks-Sills, L., Freed, Y., and Alperovitch, A. "Behavior of a Flat Internal Delamination within a Fiber Reinforced Cross-Ply Composite," International Journal of Fracture, Vol. 155, No. 2, 2009, pp. 127-142.

75. Rogel, L., and Banks-Sills, L. "A through Interface Crack between a Transversely Isotropic Pair of Materials $\left(+30^{\circ} /-60^{\circ},-30^{\circ} /+60^{\circ}\right)$," Engineering Fracture Mechanics, Vol. 77, No. 16, 2010, pp. 3261-3291.

76. Smith, S. A. "Vacuum Assisted Resin Transfer Molding of Sandwich Structures: Material Processing, Evaluation, Fracture Testing and Analysis," Ph.D. Thesis. North Carolina A\&T State University, 2001.

77. Sun, C. T., and Yang, Z. "K-Dominance in Delamination Cracks," Proceedings of the American Society for Composites - 16th Technical Conference on Composite Materials. Blacksburg, VA, 2001.

78. Krueger, R., Ratcliffe, J. G., and Minguet, P. J. "Analysis of Composite Panel-Stiffener Debonding Using a Shell/3d Modeling Technique." NIA Report No. 2007-07, NASA/CR-2007214879, NASA Langley Research Center, Hampton, VA, 2007.

79. Davidson, B. D., and Sundararaman, V. "A Single Leg Bending Test for Interfacial Fracture Toughness Determination," International Journal of Fracture, Vol. 78, 1996, pp. 193-210.

80. Krüger, R. "Three Dimensional Finite Element Analysis of Multidirectional Composite Dcb, Slb and Enf Specimens." ISD-Report No. 94/2, Institute for Statics and Dynamics of Aerospace Structures, University of Stuttgart, 1994.

81. Davidson, B. D., Krüger, R., and König, M. "Three Dimensional Analysis of Center Delaminated Unidirectional and Multidirectional Single Leg Bending Specimens," Composites Science and Technology, Vol. 54, No. 4, 1995, pp. 385-394. 
82. Davidson, B. D., Krüger, R., and König, M. "Three Dimensional Analysis and Resulting Design Recommendations for Unidirectional and Multidirectional End-Notched Flexure Tests," $J$. Composite Materials, Vol. 29, No. 16, 1995, pp. 2108-2133.

83. Davidson, B. D., Hu, H., and Schapery, R. A. "An Analytical Crack-Tip Element for Layered Elastic Structures," Jounal of Applied Mechanics, Vol. 62, No. 6, 1995, pp. 243-253.

84. Davidson, B. D. "Analytical Determination of Mixed-Mode Energy Release Rates for Delamination Using a Crack Tip Element," Fracture of Composites. Vol. 120-121, Trans Tech Publications, 1996, pp. 161-180.

85. Yu, L., and Davidson, B. D. "A Three-Dimensional Crack Tip Element for Energy Release Rate Determination in Layered Elastic Structures," Journal of Composite Materials, Vol. 35, No. 6, 2001, pp. 457-488.

86. Davidson, B. D., Yu, L. Y., Lundberg, S. D., and Rao, L. M. "Accuracy Assessment of a ThreeDimensional, Crack Tip Element Based Approach for Predicting Delamination Growth in Stiffened-Skin Geometries," International Journal of Fracture, Vol. 132, No. 1, 2005, pp. 1-32.

87. Davidson, B. D., and Yu, L. "Energy Release Rate Prediction in Stiffened-Skin Structure Using a Three-Dimensional Crack Tip Element Analysis," Journal of Composite Materials, Vol. 39, No. 20, 2005, pp. 1819-1842.

88. Davidson, B. D., Gharibian, S. J., and Yu, L. "Evaluation of Energy Release Rate-Based Approaches for Predicting Delamination Growth in Laminated Composites," International Journal of Fracture, Vol. 105, 2000, pp. 343-365.

89. Davidson, B. D., and Zhao, W. "An Accurate Mixed-Mode Delamination Failure Criterion for Laminated Fibrous Composites Requiring Limited Experimental Input," Journal of Composite Materials, Vol. 41, No. 6, 2007, pp. 679-702.

90. Davidson, B. D., Fariello, P. L., Hudson, R. C., and Sundararaman, V. "Accuracy Assessment of the Singular-Field-Based Mode-Mix Decomposition Procedure for the Prediction of Delamination," Composite Materials: Testing and Design, Thirteenth Volume, ASTM STP 1242, 1997, pp. 109-129.

91. Suo, Z., and Hutchinson, J. W. "Interface Crack between Two Elastic Layers," International Journal Fracture Mechanics, Vol. 43, 1990, pp. 1-18.

92. Hutchinson, J. W., and Suo, Z. "Mixed Mode Cracking in Layered Materials," Advances in Applied Mechanics, Vol. 29, 1992, pp. 64-191.

93. Davidson, B. D., Yu, L., and Hu, H. "Determination of Energy Release Rate and Mode Mix in Three-Dimensional Layered Structures Using Plate Theory," International Journal of Fracture, Vol. 105, 2000, pp. 81-104.

94. Mikulik, Z., Kelly, D. W., Thomson, R. S., and Prusty, B. G. "Fracture Mechanics Based Predictions of Initiation and Growth of Multi-Level Delaminations in a Composite Specimen," International Journal of Fracture, Vol. 170, 2011, pp. 145-157.

95. Carlsson, L. A., and Prasad, S. "Interfacial Fracture of Sandwich Beams," Engineering Fracture Mechanics, Vol. 44, No. 4, 1993, pp. 581-590.

96. Smith, S. A., and Shivakumar, K. N. "Modified Mode-I Cracked Sandwich Beam (Csb) Fracture Test," The 42nd AIAA/ASME/ASCE/AHS/ASC Structures, Structural Dynamics, and Materials Conference, Seattle, WA. AIAA-2001-1221, American Institute of Aeronautics and Astronautics, 2001.

97. Wang, J., and Zhang, C. "Energy Release Rate and Phase Angle of Delamination in Sandwich Beams and Symmetric Adhesively Bonded Joints," International Journal of Solids and Structures, Vol. 46, No. 25-26, 2009, pp. 4409-4418.

98. Berggreen, C., and Simonsen, B. C. "Non-Uniform Compressive Strength of Debonded Sandwich Panels - Ii. Fracture Mechanics Investigation," Journal of Sandwich Structures and Materials, Vol. 7, 2005, p. 483.

99. Berggreen, C., Simonsen, B. C., and Borum, K. K. "Experimental and Numerical Study of Interface Crack Propagation in Foam-Cored Sandwich Beams," Journal of Composite Materials, Vol. 41, No. 4, 2007, pp. 493-520.

100. Matos, P. P. L., McMeeking, R. M., Charalambides, P. G., and Drory, M. D. "A Method for Calculating Stress Intensities in Bimaterial Fracture," International Journal of Fracture, Vol. 40, 1989, pp. 235-254.

101. Østergaard, R. C., and Sørensen, B. F. "Interface Crack in Sandwich Specimen," Int. J. Fracture, 
Vol. 143, 2007, pp. 301-316.

102. Østergaard, R. C., Sørensen, B. F., and Brønsted, P. "Measurement of Interface Fracture Toughness of Sandwich Structures under Mixed Mode Loadings," International Journal of Sandwich Structures, Vol. 9, No. 5, 2007, pp. 445-466.

103. Manca, M., Quispitupa, A., Berggreen, C., and Carlsson, L. A. "Face/Core Debond Fatigue Crack Growth Characterization Using the Sandwich Mixed Mode Bending Specimen," Composites Part A: Applied Science and Manufacturing, Vol. 43, No. 11, 2012, pp. 2120-2127.

104. Moslemiana, R., Karlsson, A. M., and Berggreen, C. "Accelerated Fatigue Crack Growth Simulation in a Bimaterial Interface," International Journal of Fatigue, Vol. 33, No. 12, 2012, pp. 1526-1532. 


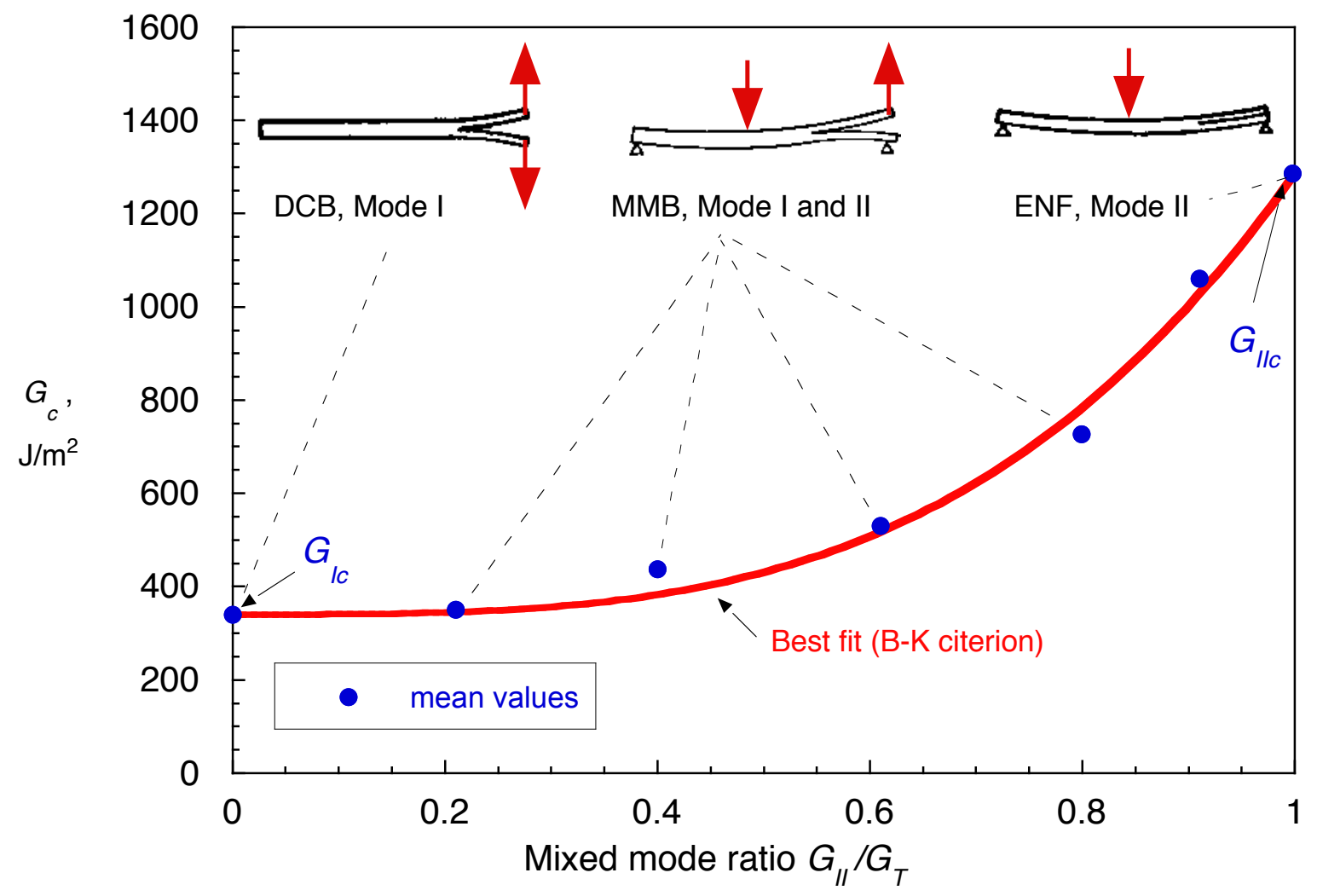

Figure 1. Mixed-mode failure criterion for a typical carbon/epoxy material. 


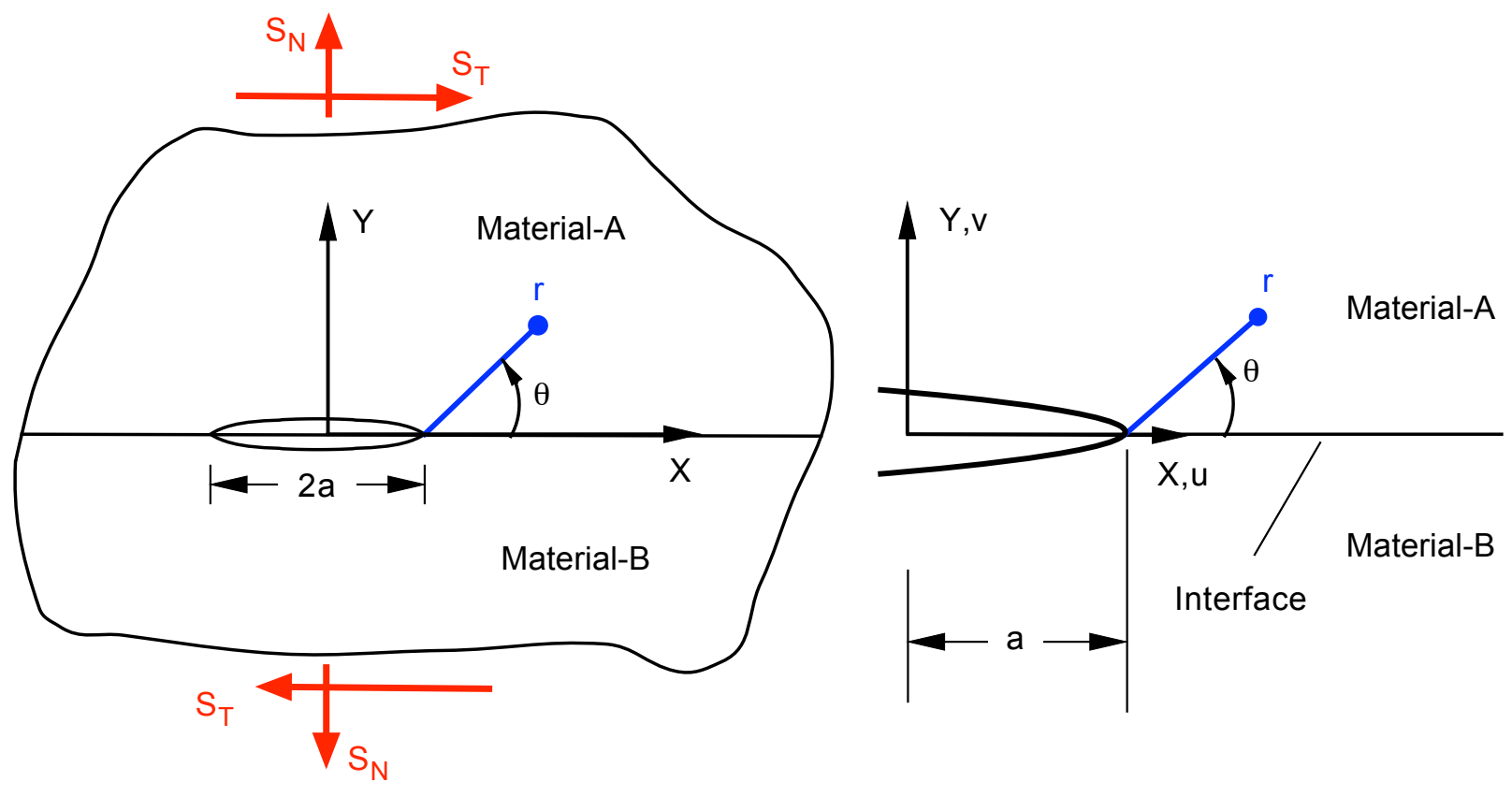

Figure 2: Crack located at a bimaterial interface. 


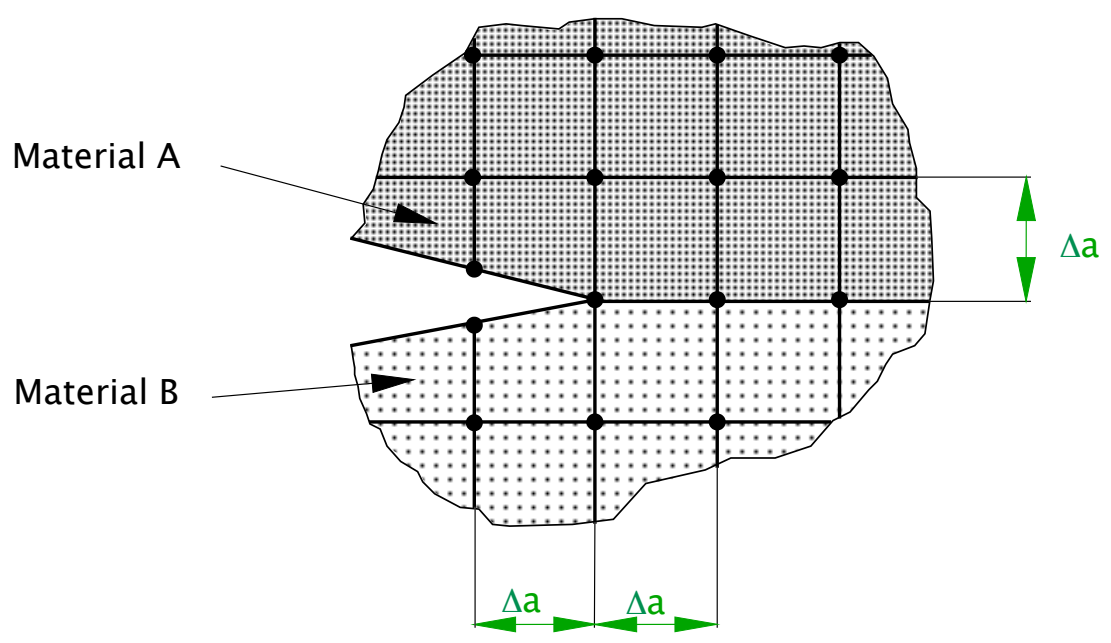

Figure 3: Virtual crack closure at bimaterial interface. 


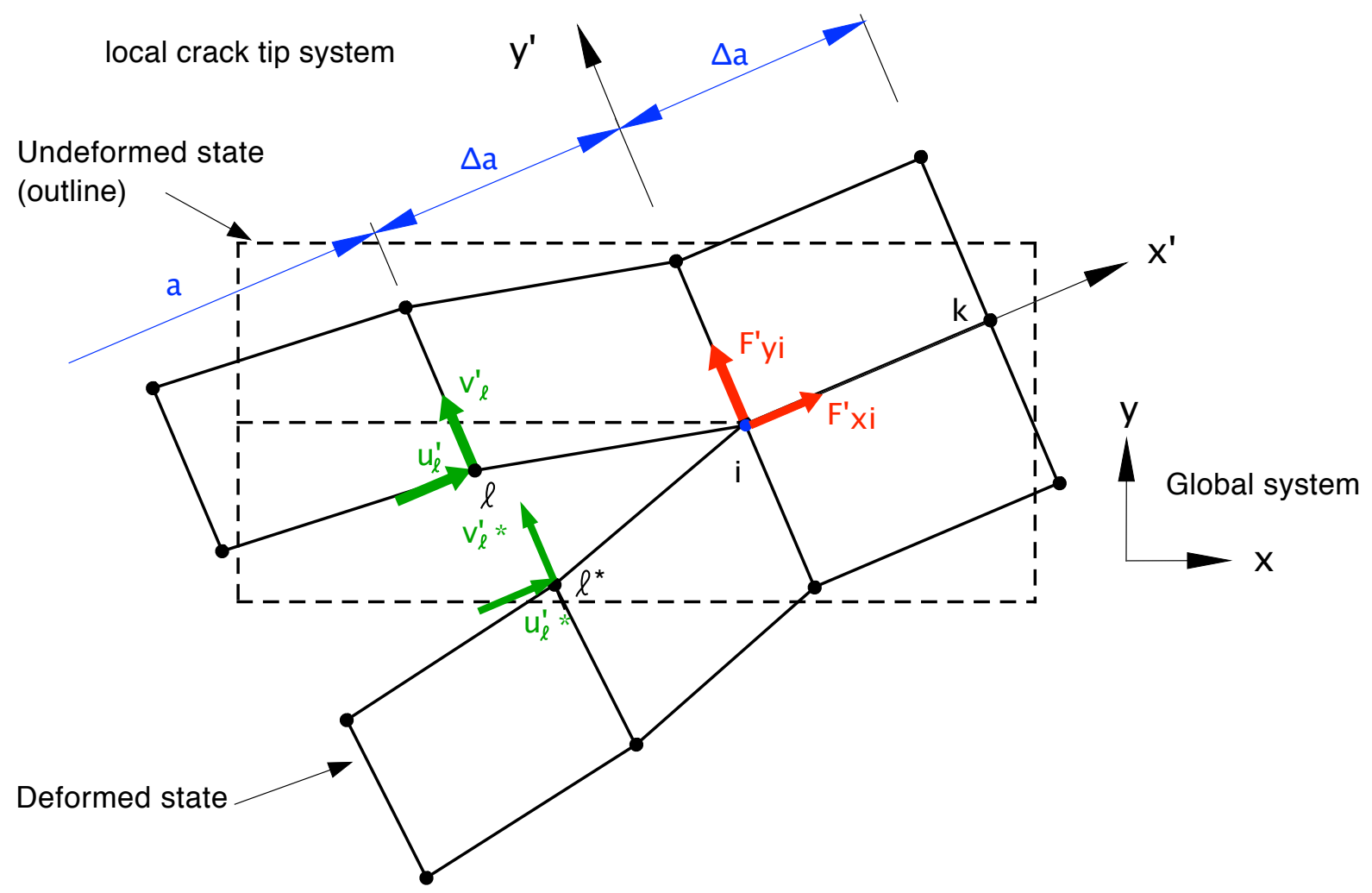

a. VCCT for geometrically nonlinear analysis using 4-node 2D elements.

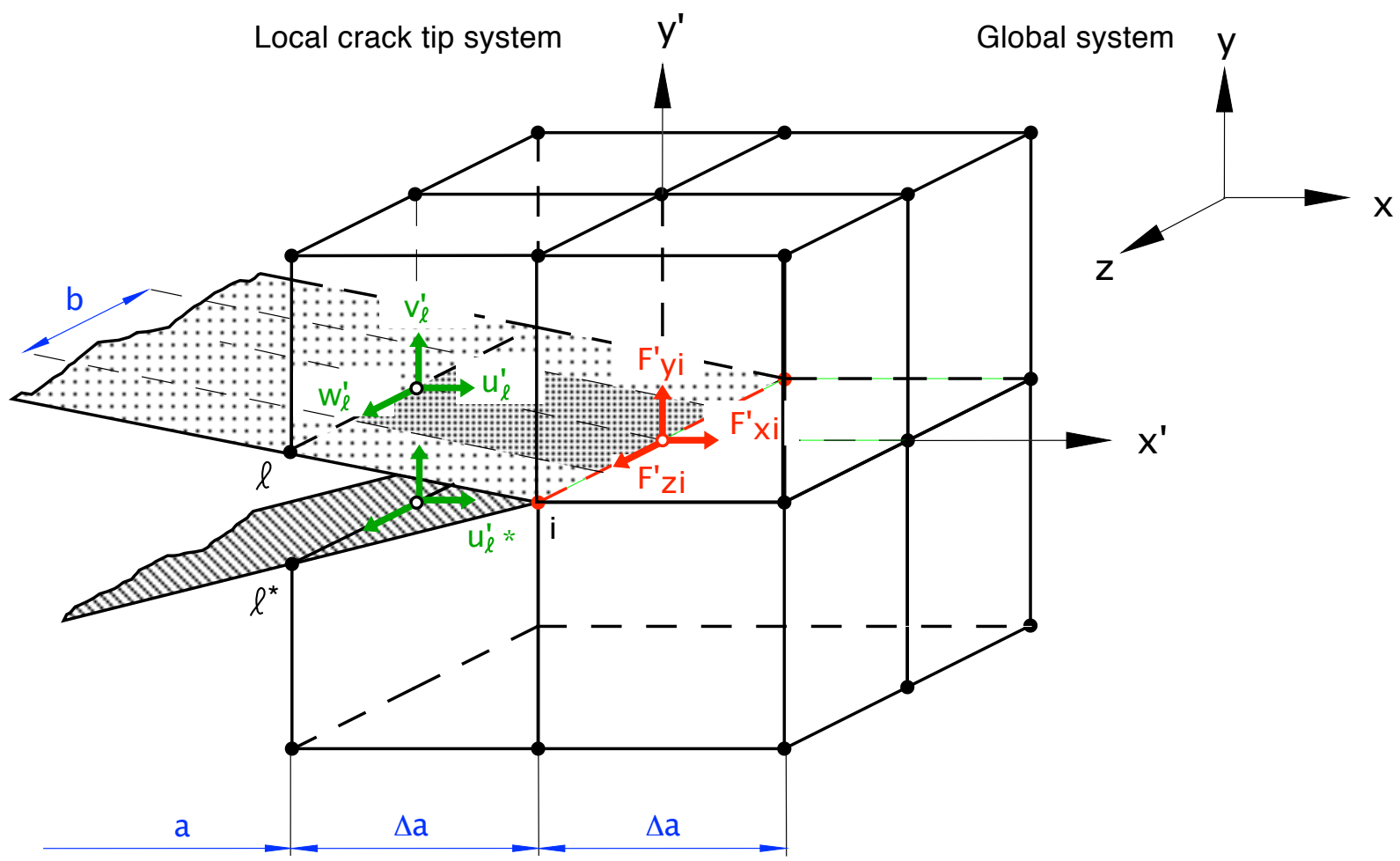

b. VCCT for eight node 3D solid elements.

Figure 4. Virtual Crack Closure Technique (VCCT) [17,18]. 


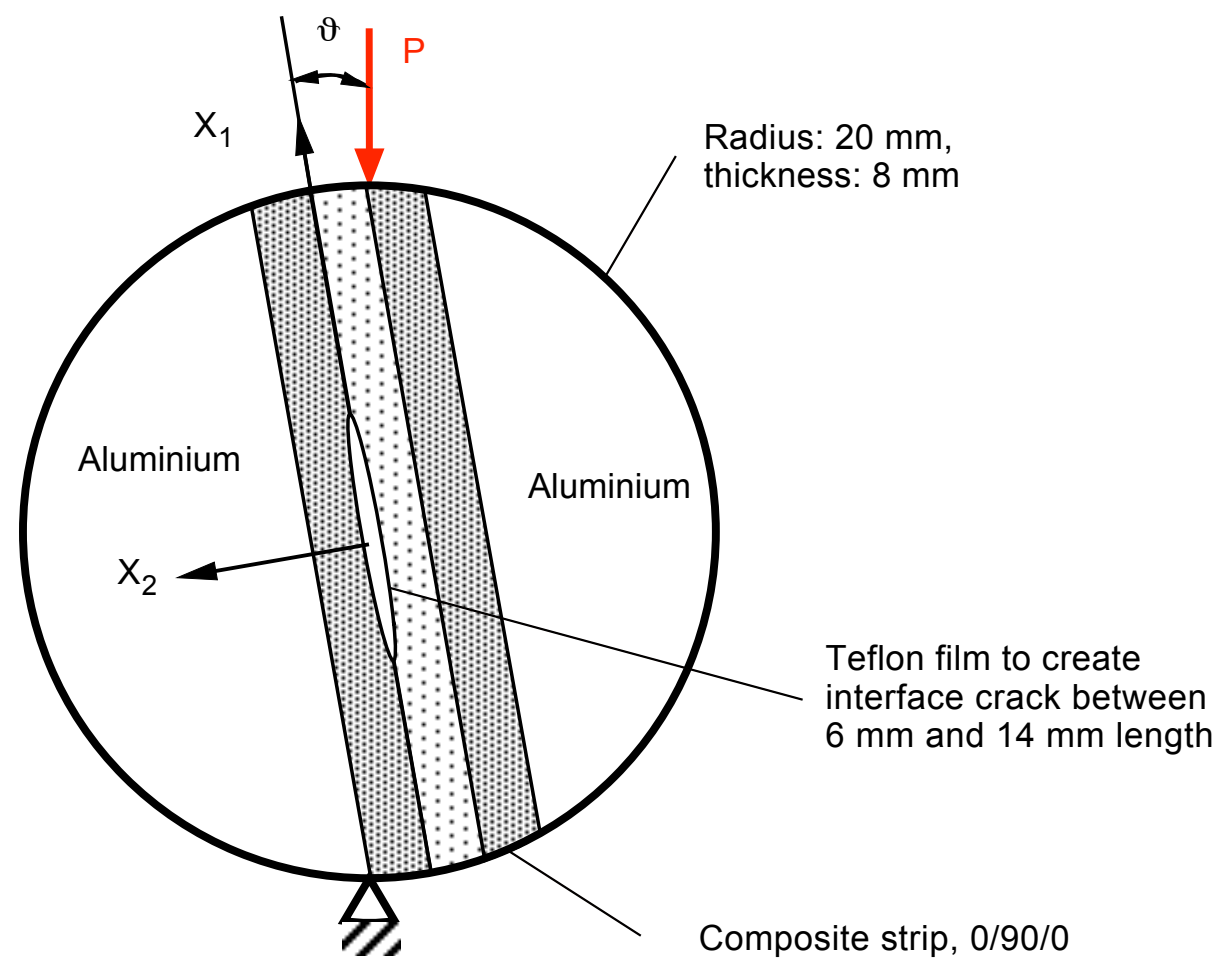

Figure 5: Sketch of a Brazilian disk specimen containing a composite strip with a crack along a 0/90 interface [69,74]. 


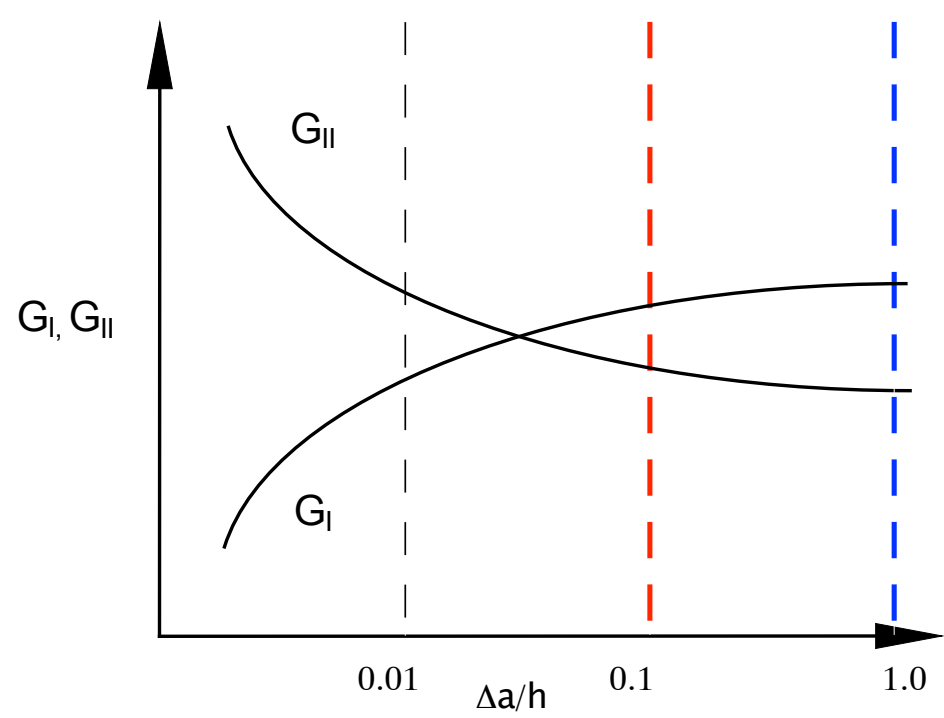

$\Delta$ a: Element length h: Ply thickness

(a). Dependence of computed energy release rate components on element size near the crack tip.
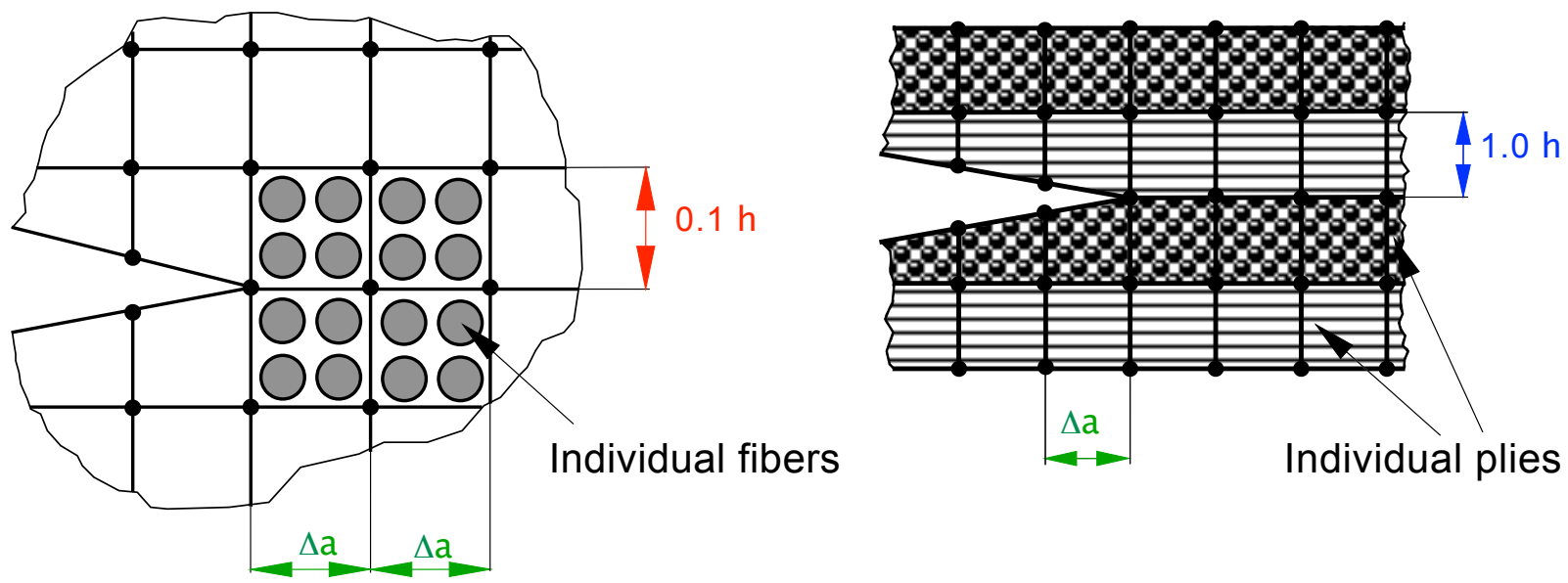

(b). Upper and lower bounds for element size at crack tip

Figure 6: Influence of element size on computed mode components. 


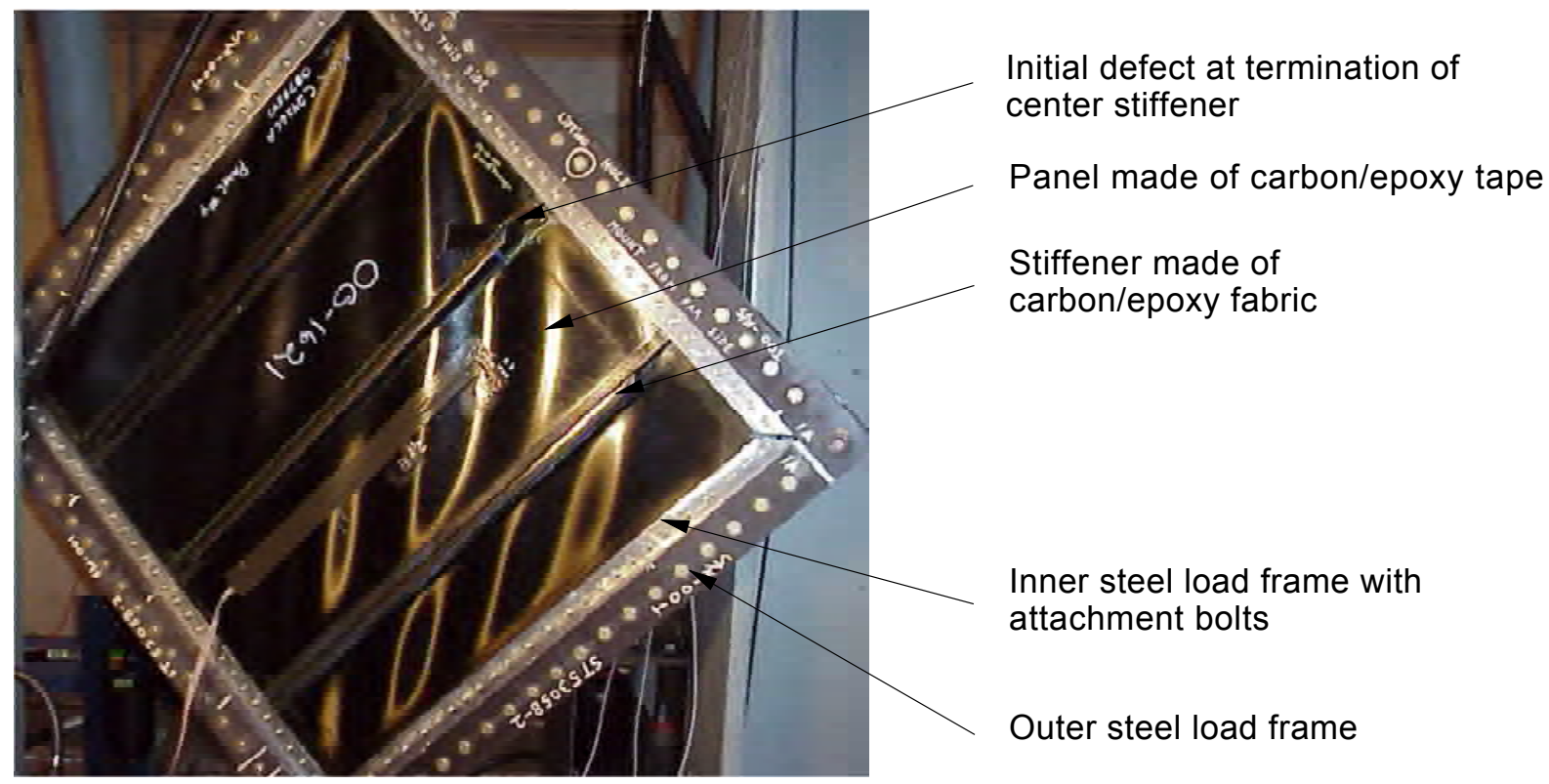

(a). Buckled composite panel under shear loading with picture frame.

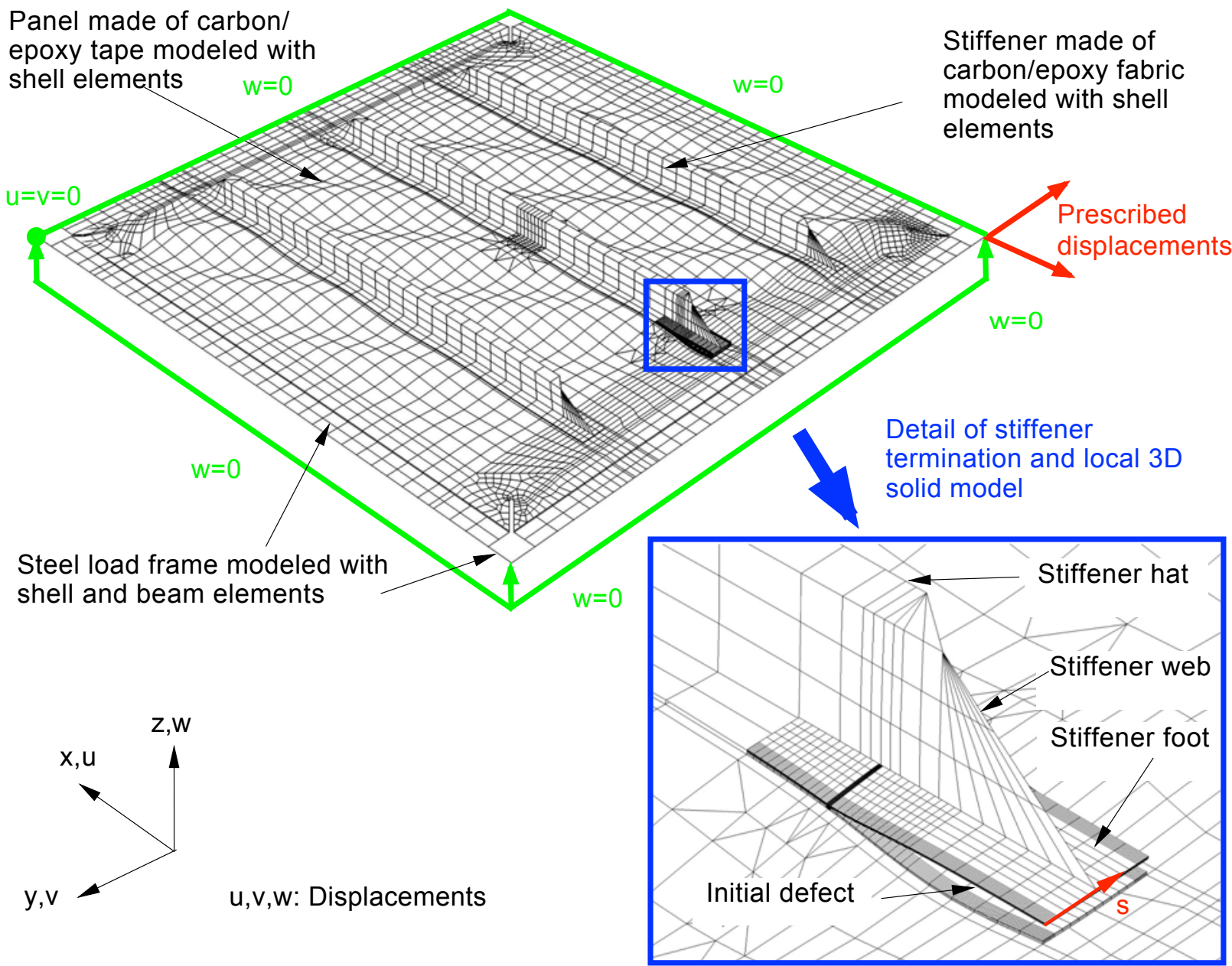

(b). Finite Element model of stiffened panel and load frame.

Figure 7. Stiffened composite panel [78]. 


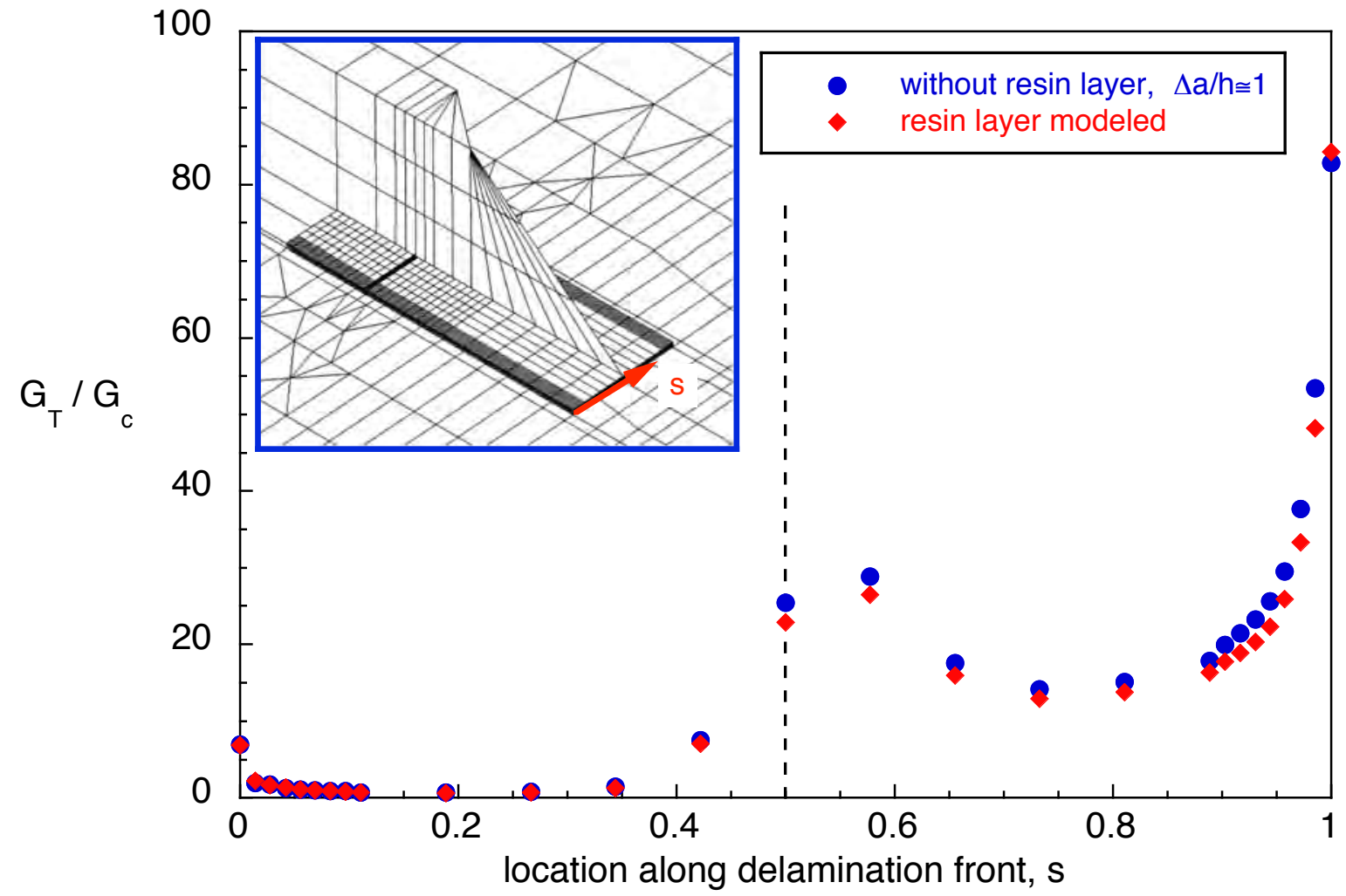

Figure 8. Computed failure index across the width of the stiffener for models with and without a resin layer [78]. 


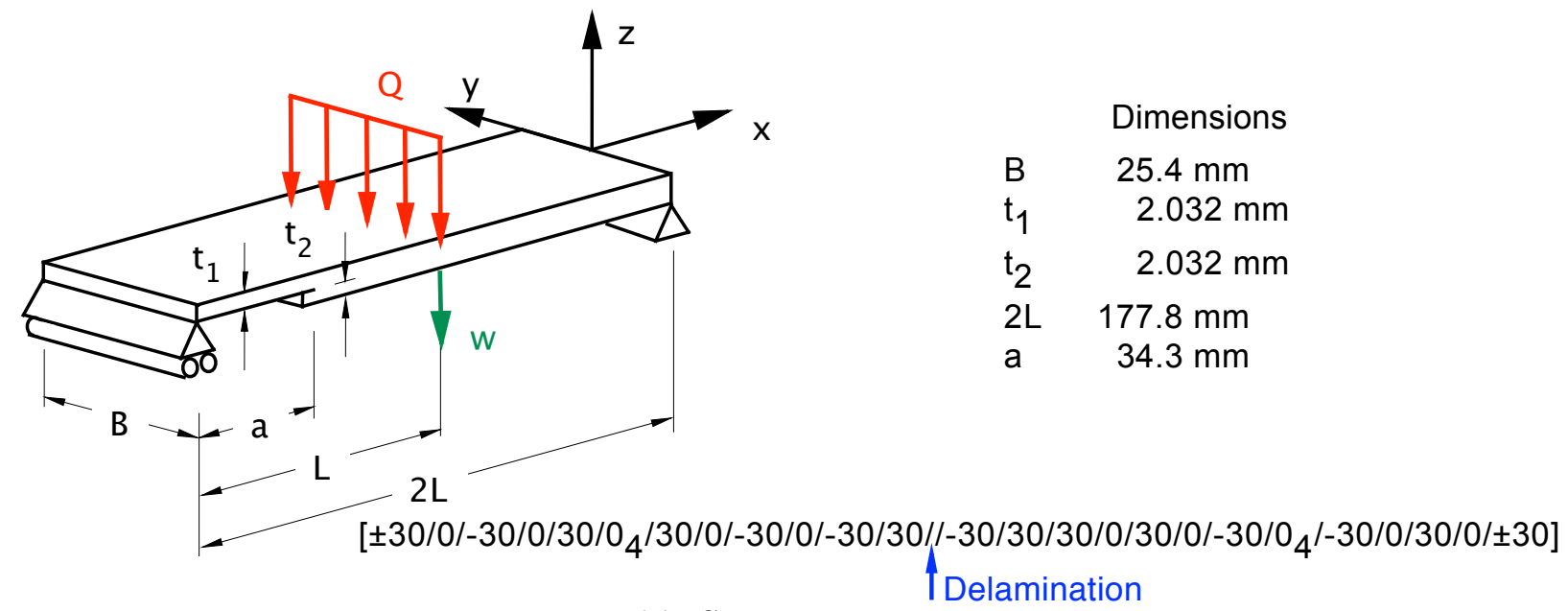

(a). SLB specimen

Outline of undeformed configuration

$\mathrm{w}_{\mathrm{c}}$ : deflection in the center of the specimen

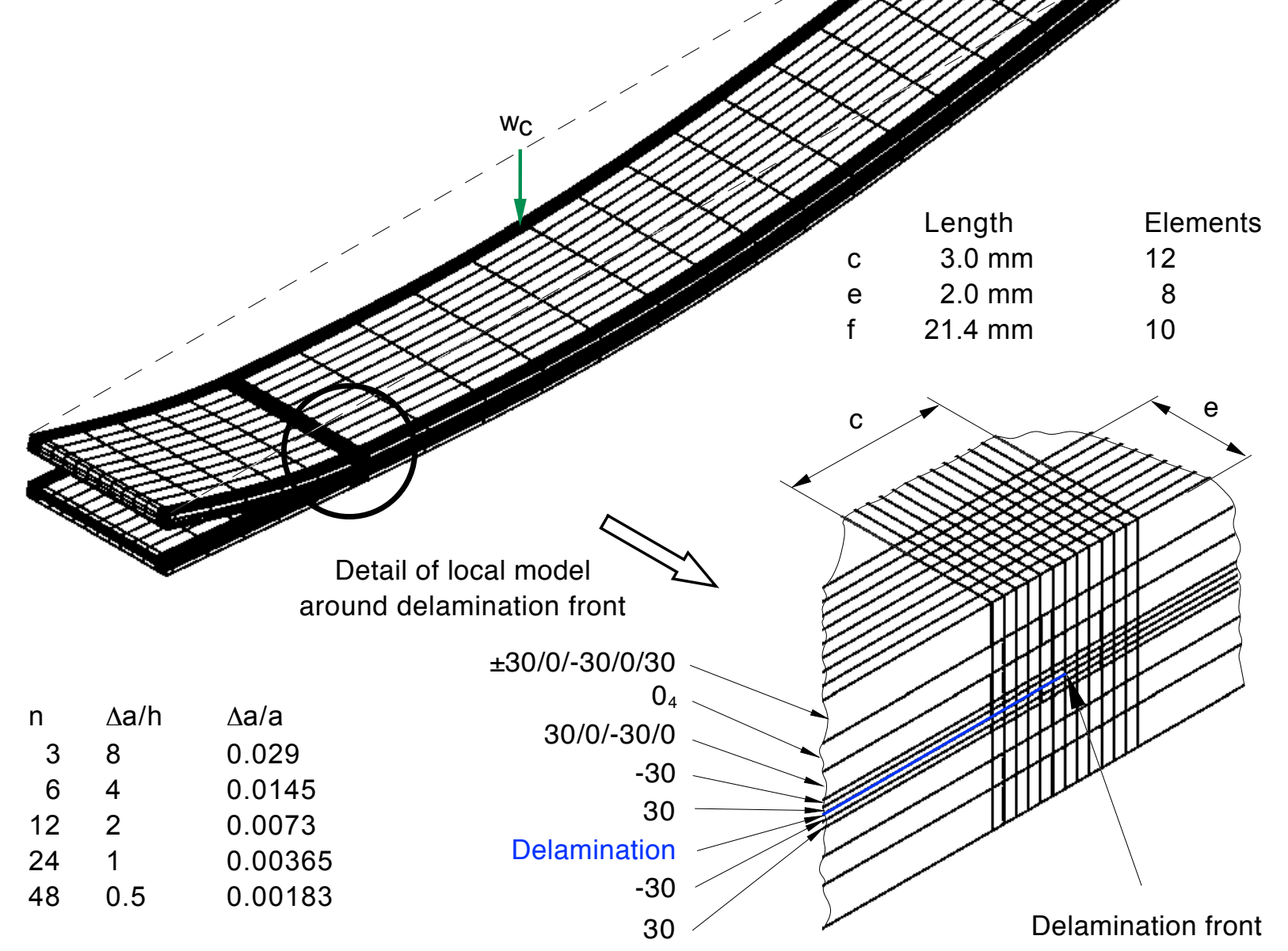

(b). Three-dimensional finite element model of a SLB specimen with detail.

Figure 9. Finite element analysis of a Single Leg Bending Specimen (SLB) [18, 80, 81]. 


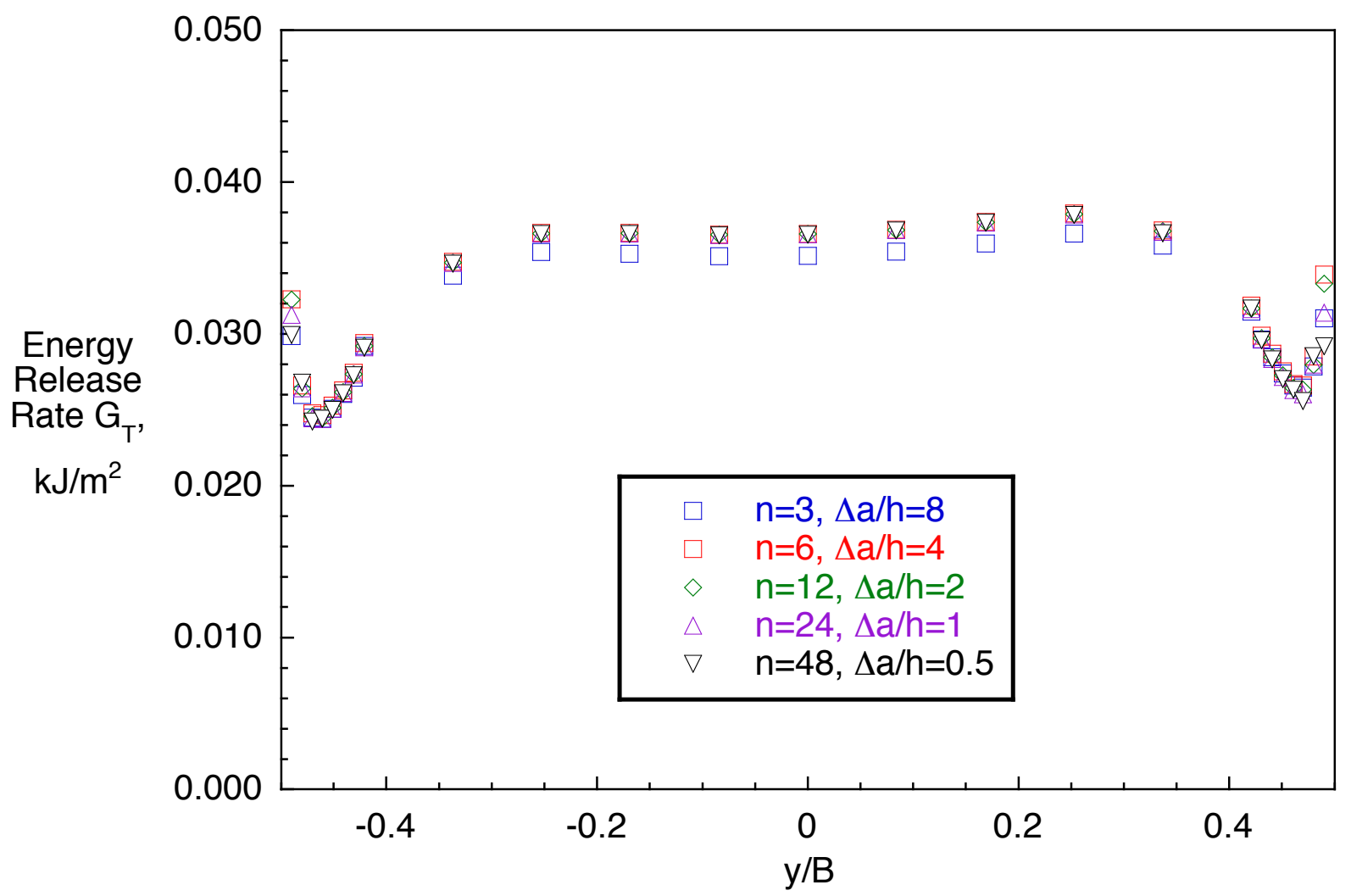

Figure 10. Influence of number of elements in refined section on computed total strain energy release rate distribution across the width of a SLB specimen [18].

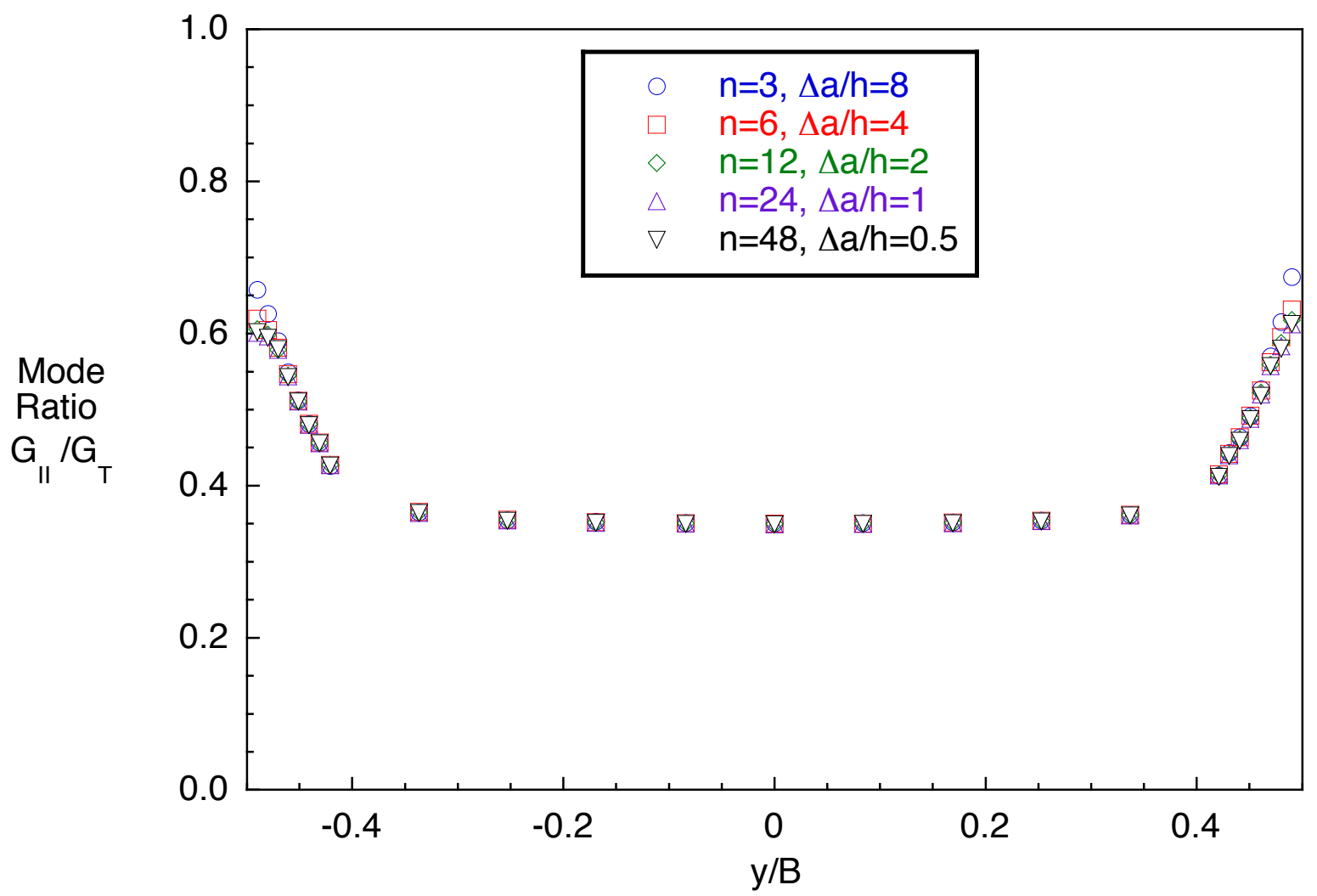

Figure 11. Influence of number of elements in refined section on mode ratio distribution across the width of a SLB specimen [18]. 


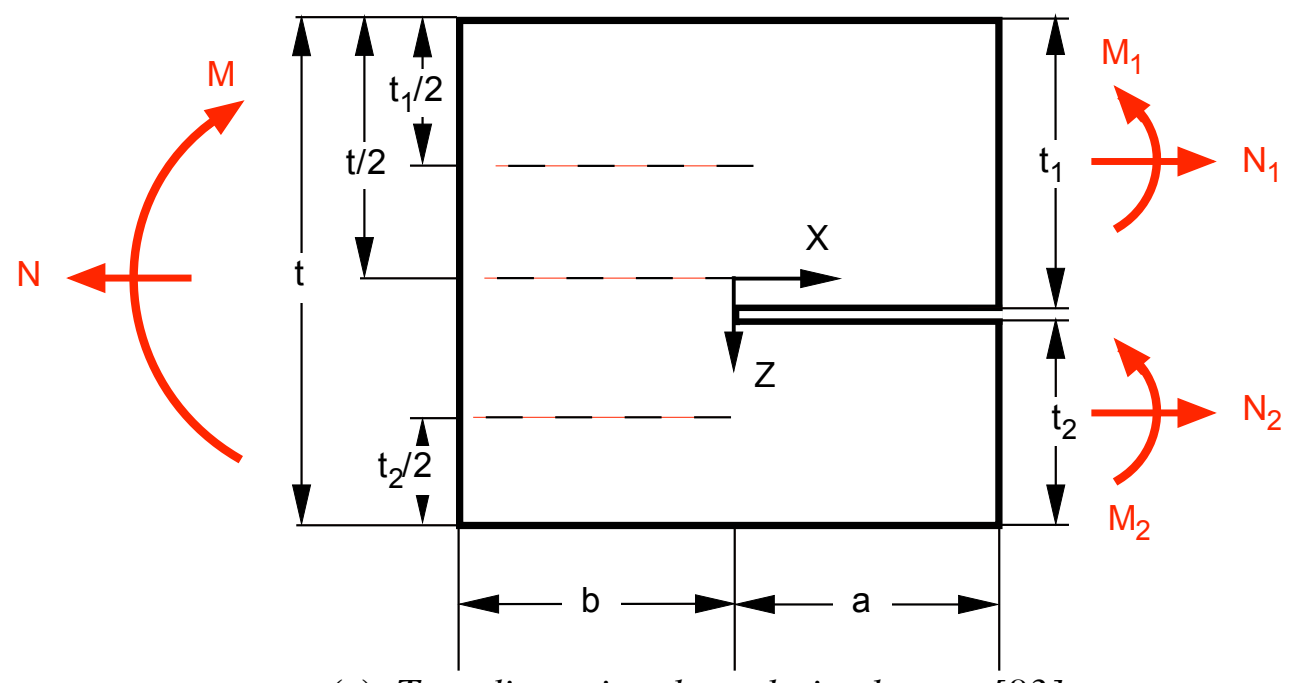

(a). Two-dimensional crack-tip element [83].

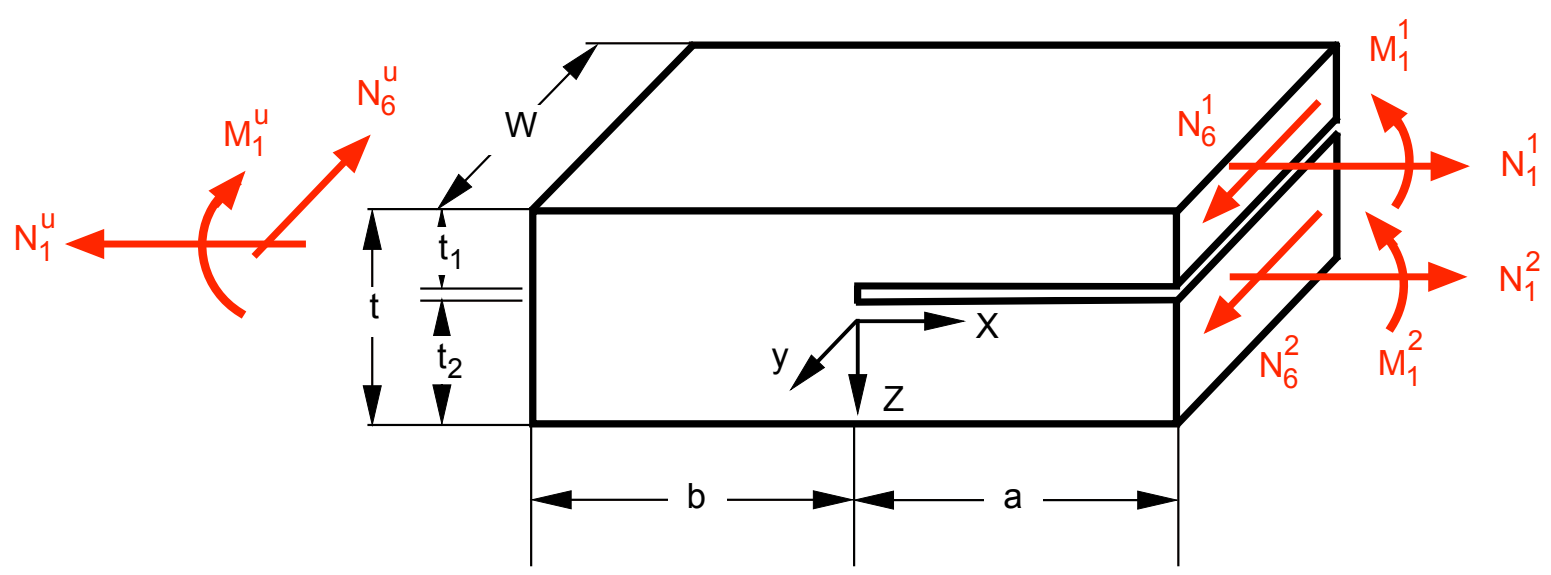

(b).: Three-dimensional crack-tip element [85, 86].

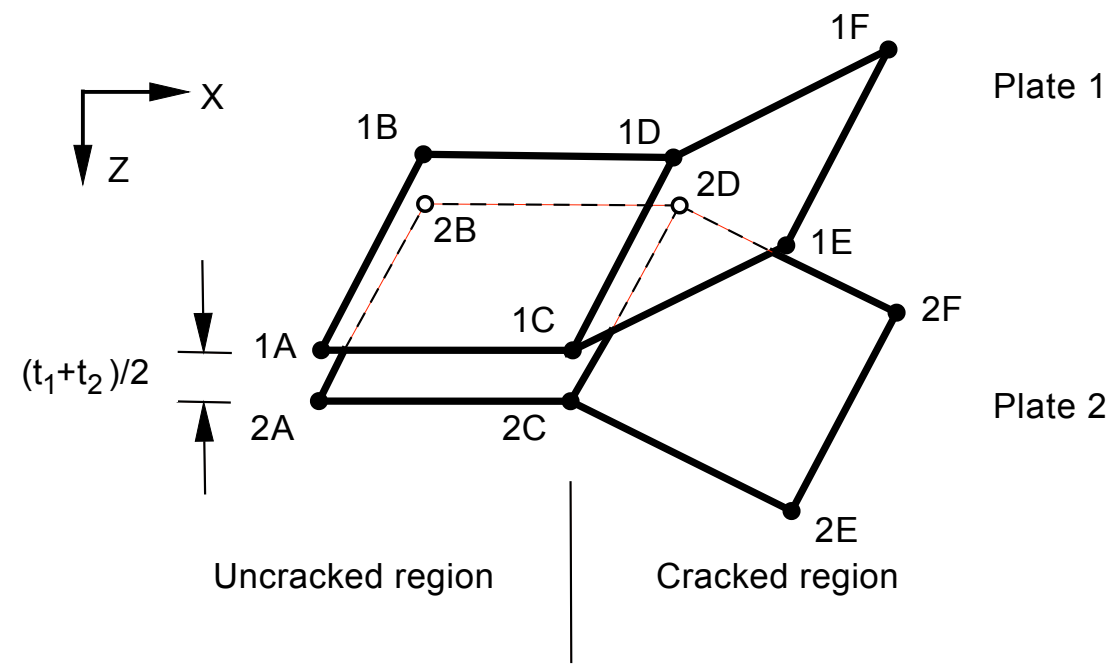

(c). Four finite plate elements adjacent to the crack front in a double plate model [88].

Figure 12: Crack-tip element approach suggested by Davidson. 


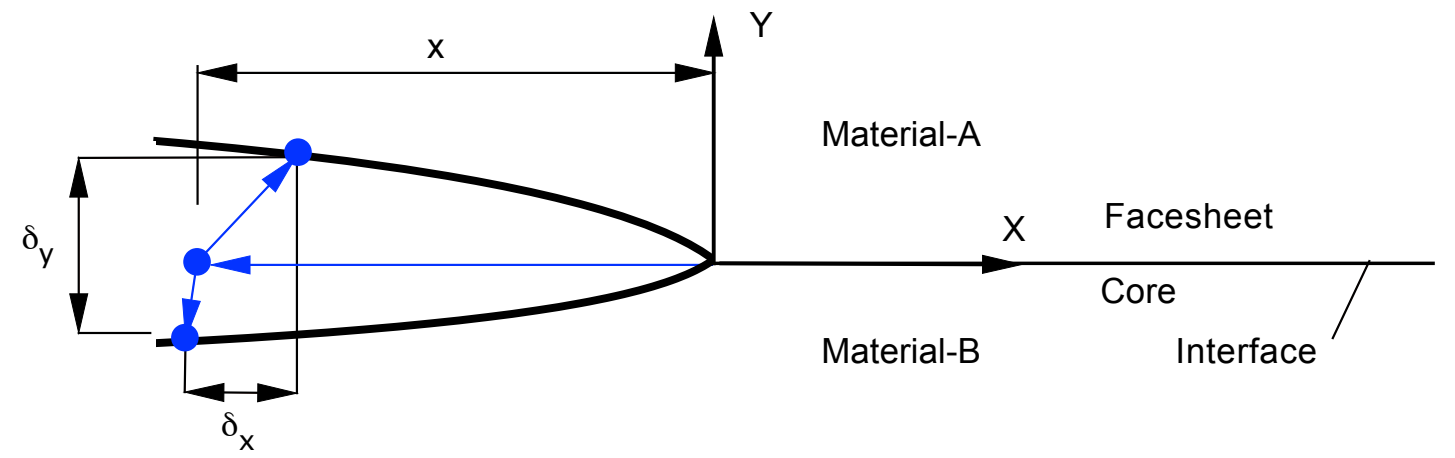

(a). Sandwich bimaterial interface and crack tip geometry.

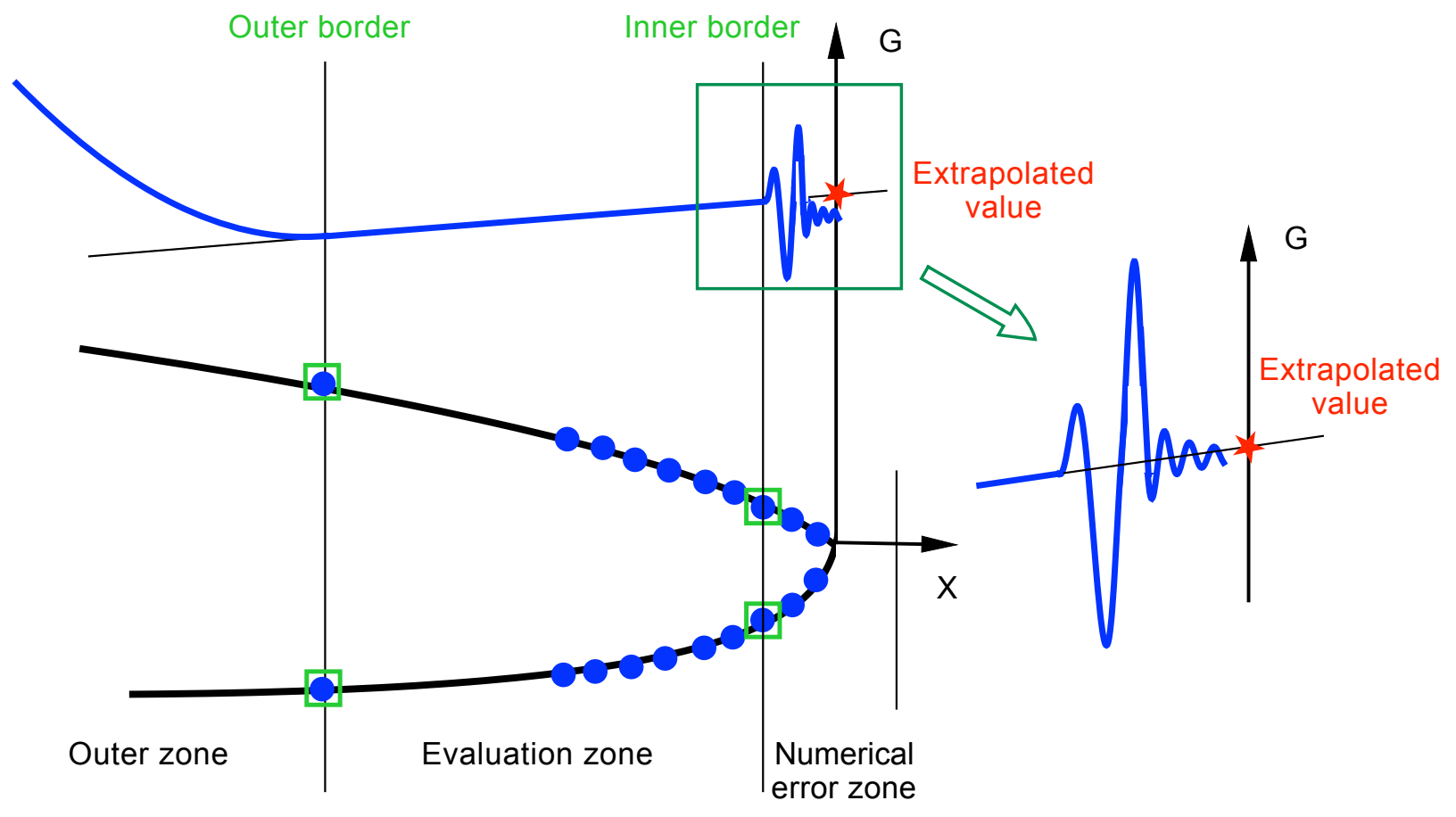

(b). Detail of evaluation zone.

Figure 13: Schematic of the crack surface displacement extrapolation method [98, 99]. 